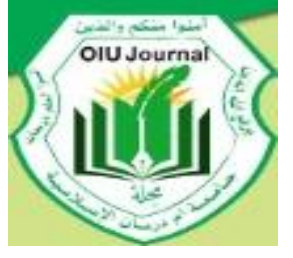

2018; 14(1): 65-94
Omdurman Islamic University Journal(OIUJ)

\section{مجلة جامعة أم درمان الكسلامية}

https://journal.oiu.edu.sd/index.php/oiuj

https://doi.org/ 10.52981/oiuj.v14i1.1613

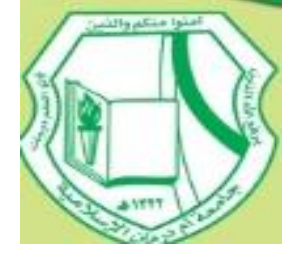

ISSN: 5361-1858

\title{
المنظور الإسلامي للاتكيت
}

د. محمد يوسف إبراهيم (*)

أستاذ مساعد بقسم الآعوة والإعلام ـ كلية العوم الإسلامية والعربية -جامعة سنار.

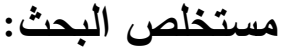

أصبح الإتكيت مظهراً من مظاهر الحضارة المعاصرة وقد احتل مكاناً بارزاً في مجال العلاقات الدولية خاصة على مستوى التعامل الدبلوماسي في جانب البروتكول والمراسم،

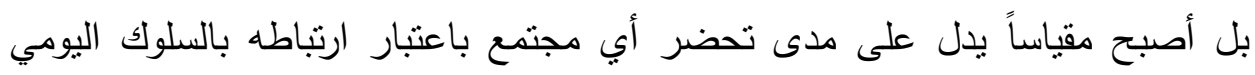

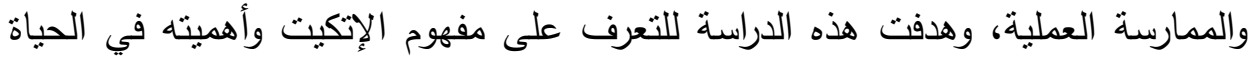

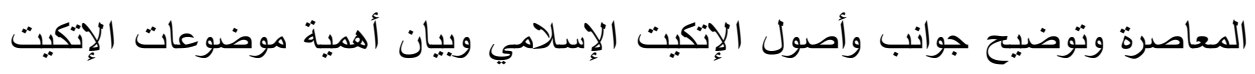
الإسلامي ودورها في التربية والتهذيب، وتم استخدام المنهج الوصفي لملائمته مع هذا الإنا

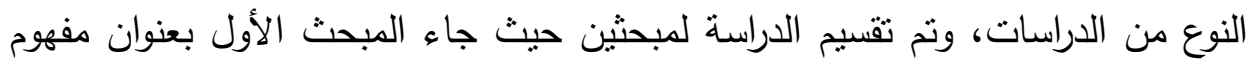

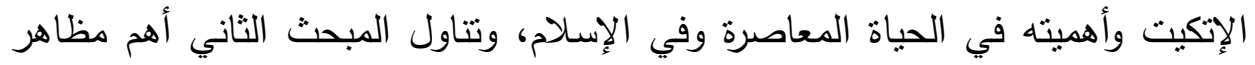

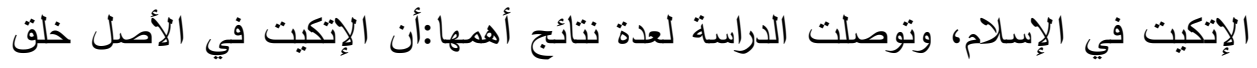

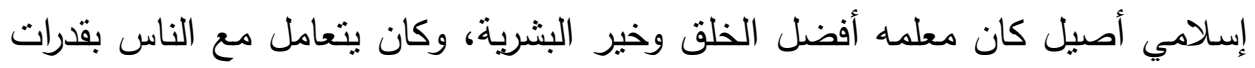

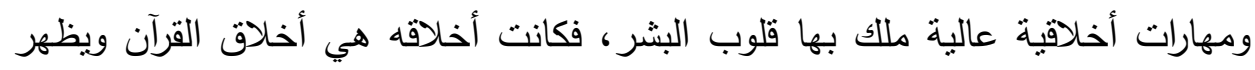

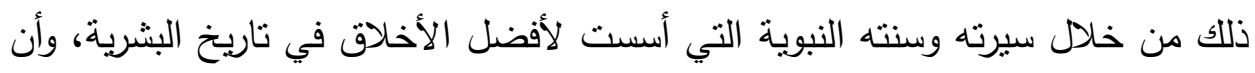

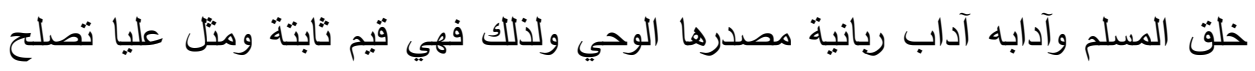
لكل إنسان بصرف النظر عن جنسه وزمانه ومكانه، ومن ثم فقد وضعت الدابه الدراسات عدات

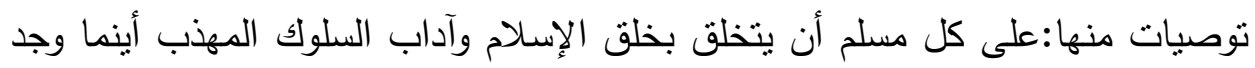

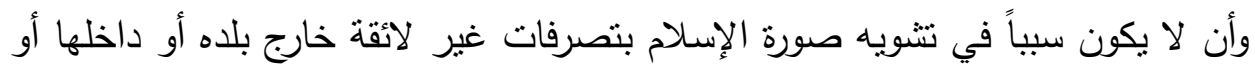

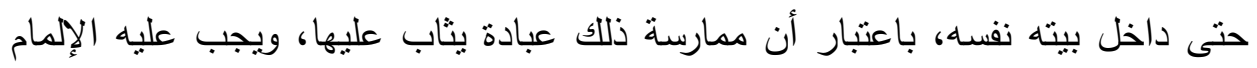

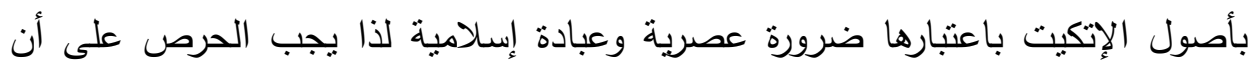




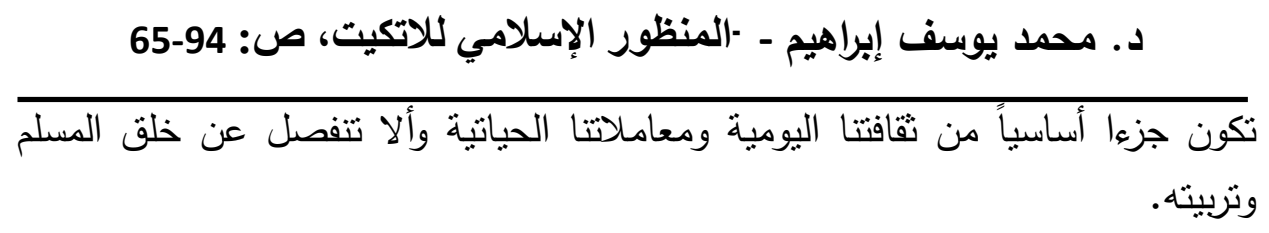

\section{Abstract}

Etiquette has become manifestation of modern civilization and has taken prominent place in the field of international relations especially on the level of diplomatic dealings, on the side of protocol and ceremony, it has become a measure of the extent to which any society is brought into consideration as it relates to daily behavior and practice, the purpose of this study is to identify the concept of etiquette and its importance in contemporary life, to clarify the aspects and origins of Islamic etiquette, and to explain the importance of its role in education and refinement, the descriptive approach was used to suit this type of study, which was divided into two sections, the first topics was entitled (the concept of etiquette and its importance in contemporary life and Islam),the second topic dealt with the most important aspects of etiquette in Islam, the study reached several results the most important that, the etiquette originally an authentic Islamic teacher who was the best creation and best mankind, his ethics were the ethics of Quran and this is shown through his biography and his prophetic (sunah) which established the best ethics in the history of mankind, Muslims morality and his moral character is considered as a gift from God, the divine source of revelation is therefore affixed values and ideals suitable for everyone regardless of sex, time and place, therefore the studies have made several recommendations, every Muslim must have the ethics of Islam and the manners of polite behavior where ever he may be, and not be areson of distort the image of Islam by in appropriate behavior outside his country or within or even his own home, considering that the practice of worship is rewarded on their performance, and he have to know the origins of the etiquette as modern necessity and Islamic worship, there fore care must be taken to be an essential part of our daily culture and our life processes and not separate from Muslims creation and educations. 


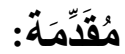

تختلف قواعد السلوك الاجتماعي باختلاف الجماعات والأمم واختلاف العصور، حيث أن مرجعيتها هي التقافة الإنسانية ففي وسع كل جماعة أن تذّعي أن سلوكها الاجتماعي هو المثل الأعلى وبظهر ذلك حتى في الشعوب البدائية التي لها قواعدها وعاداتها، والأخلاق الفاضلة متمنلة في الآداب والسلوك المهذب هي التي تبني أفراد الأمم والثعوب وتمثل المعاقد الثابتة التي تعقد بها الروابط الاجتماعية، فالأخلاق الاجتماعية تحدد للمجتمع أهدافه وقيمة العليا ومبادئه الثابتة التي تسهل على الناس حياتهم وتحفظ لهم استقرارهم وأمنهم وكيانهم في إطار موحد.

ونجد ان الثرائع السابقة كلها تحث على الأخلاق الفاضلة ونتفق عليها، ولكن الثربعة الكاملة جاء النبي صلى الله عليه وسلم فيها بتمام مكارم الأخلاق ومحاسن الخصال وتحسين سلوك وآداب الإنسان والرقي به نحو مجتمع حضاري منكامل فوضع أسساً وقواعد لتعامل الإنسان فيما بينه وبين نفسه أو فيما بينه وبين كل ما يحيط به ثقوم في مجملها على الذوق العام وحسن الخلق وهذا ما بطلق عليه اليوم"الإتكيت" أي فن التعامل مع الناس ومع الأشياء. وقد وصل هذا الخلق والسلوك النبوي إلي بلاد الأندلس عن طريق المسلمين، وبعد سقوط دولة الأندلس اهتمت به دول كثيرة منها فرنسا وإسبانيا وبربطانيا وأضافوا له الكثير، حتى وصل إلينا بهذه الصورة ومنه الإتكيت الدولي والبروتوكول الذي هو أكثر صرامة وبهتم بكل صغيرة وكبيرة في المعاملات الرسمبة. وقد كان لخلق وتعامل المسلمين دور كبير في دخول العديد من الأفراد إلي دين الإسلام فقد كان انتشار الإسلام في بعض الدول عن طريق التجارة والدعاة وحسن تعاملهم وخلقهم. 
د. محمد يوسف إبراهيم - -المنظور الإسلامي للاتكيث، ص: 94-65

فالإتكيت في الأصل خلق إسلامي أصيل كان معلمه أفضل معلم وخير مُربي للبشرية وهادي الأمة نبي الرحمة محمد صلى الله عليه وسلم الذي أنثي الله عليه

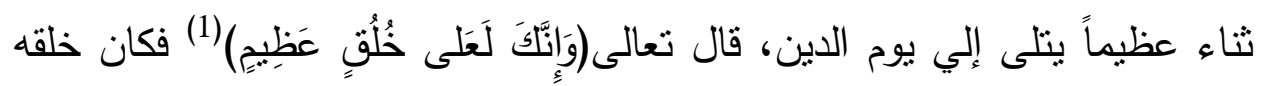

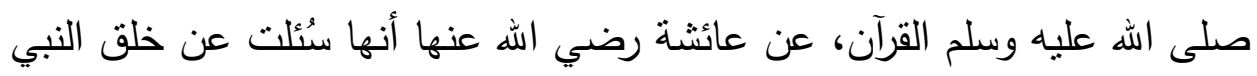
صلى الله عليه وسلم، فقالت: كَان خُلقُه الُقرَآن (2). فالإتكيت جملة آداب وأخلاق إسلامية ترتب حياة الفرد في جميع النواحي

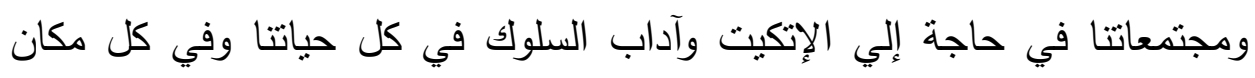
وهي تأتي من باب العبادة فالمسلم مأمور بحسن الخلق في حياته واده منذ مولده وحتى مماته. وتأتي هذه الدراسة في محاولة لتوضيح هذه الجوانب وتنين مفهوم الإتكيت وأهميته في مجتمعاتتا حتى يكون ذلك مدخلاً لتأسيس الثهود الحضاري لأمتتا (وَكَذَلِكَ

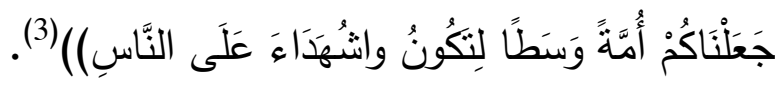

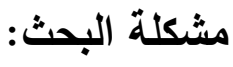

تعاني مجتمعانتا الإسلامية والعربية من كثير من المشكلات والتحديات في مختلف مأف المستويات ومن ذللك ما هو مرتبط بتحسين سلوك وآداب الإنسان والرقي بها نحون

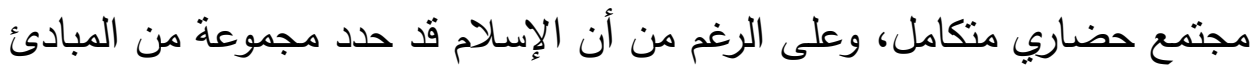
والقواعد المنظمة للسلوك الإنساني لتنظيم حياة الإنسان وتحديد علاقته بغيره على النى

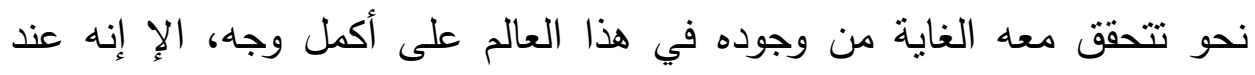
التدقيق والملاحظة نجد أن مجتمعاتتا تفرق بين الفكر والعمل والنظرية والتطبيق وبين الثعار والممارسة ولا تتخلق بخلق الإسلام وآداب السلوك المهذب بل ينت تشويه صورة الإسلام بتصرفات غير لائقة في المأكل والمشرب والملبس والسفر

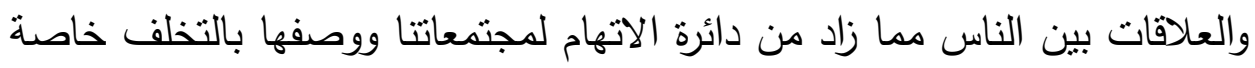
عند المقارنة بالغرب الذي نجده اليوم في قمة التقدم والإنجاز، وقد ارتبط الإتكيت 
عند البعض بأنه أحكام جامدة وتقيلة وأننا لسنا بحاجة لها ولا معني لها أو إنها

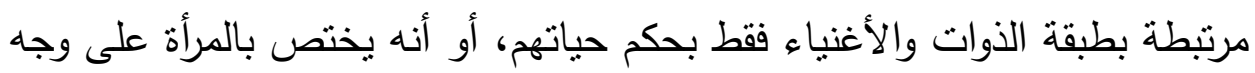
الخصوص وأن الإتكيت بعيد عن الدين وأنه يطبق في أماكن خاصة وغير ذللك

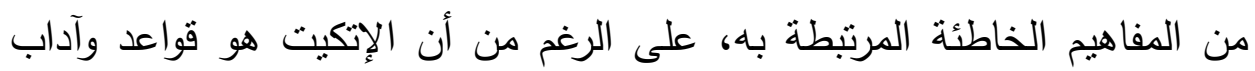

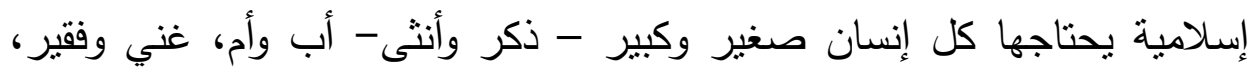
وبالتالي تتمثل المشكلة في التساؤل الرئيسي التالي: ما المنظور الإسلامي للإتكيت................

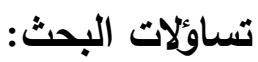

ما الإتكيت وما أهيته في الحياة العامة ؟ هل يوجد إتكيث إسلامي وما مصادره ؟

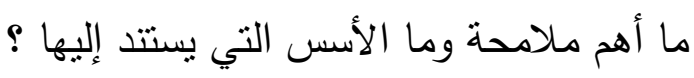

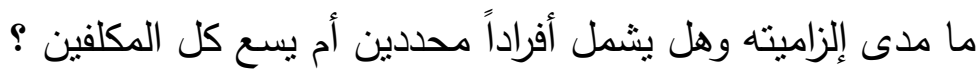
أهداف البحث: مان: التعرف على مفهوم الإتكيت وأهميته في الحياة المعاصرة توضيح جوانب وأصول الإتكيت الإسلامي بيان أهمية موضوعات الإتكيت الإسلامي ودورها في التربية والتهذيب.

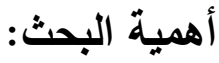

تأتي أهية هذا البحث من خلال أنه يتتاول موضوعاً عالي الأهية في الحياة اليومية المعاصرة للأفراد والجماعات ويتحدث عن الجوانب السلوكية والتربوية للأفراد والجماعات وبالتالي يتتاول جوانب الاتصال والتأثثر في العلاقات داخل المجتمع، ولقلة الكتابات المتخصصة في هذا الجانب والتي غالباً ما تكون موجودة التئي

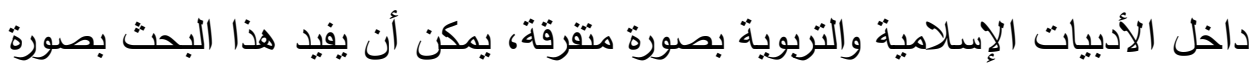


د. محمد يوسف إبراهيم - -المنظور الإسلامي للاتكيث، ص: 94-65

مباشرة في توضيح الإسهام الحضاري للإسلام في جانب العلاقات الإنسانية وبناءها على أسس سليمة من قواعد وآداب السلوك العامة الراقية. مصطاح البحث:

إلعيث" " Etiquette للإتكيت تعربفات كثيرة ومتعددة ومنتابها بدرجة كبيرة وقد اختار الباحث منها هذه التعريفات (4): مفهوم الإتيكيث في الموسوعة البريطانية: السلوك الذي يساعد الناس على الانسجام والتاؤم مع بعضهم البعض ومع البيئة التي بعيشون فيها. مفهوم الاتيكيت في الموسوعة الأميركية: الإتيكيت كلمه تعني التهذيب واللياقة وتساعد الفرد على تحسين علاقته بالآخرين. ويعرف الاتيكيت أيضاً بأنه بأنه فن الخصال الحميدة أو السلوك بالغ التهذيب وتتعلق قواعده بآداب السلوك والأخلاق والصفات الحسنة. 


\section{المبحث الأول \\ مفهوم الإتكيت وأهميته في الإسلام}

أولاً: مفهوم الإتكيت:

تمثل قواعد السلوك الاجتماعي والإجراءات والتقاليد والأعرف المتبعة بين الأفراد أصول التصرف والأخلاق الحميدة، وبما أن الأخلاق تجسد القيمة والمبادئ التي يحملها الإنسان وعليه فإن ما يختص بسلوك الفرد ويعكس قيمه ومبادئه بسمى"

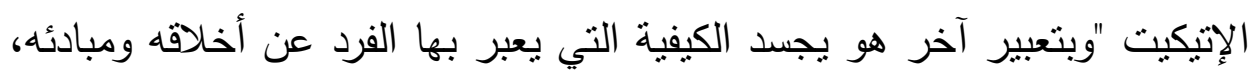
فالإتيكيت هو مجموعة تصرفات تؤدي إلى احترام النفس واحترام الآخرين وهو السلوك الذي يساعد الناس على الانسجام والتلاؤم مع بعضهم البعض ومع البيئة التي يعيشون فيها.

ولا تزال قواعد اللياقة والمجاملة تخضع بصورة تكاد تكون تامة للعرف المتواتر الأمر الذي يسمح بقدر من المرونة حسب ظروف التطور وتأثير الثقافات المحلية والمهم أن هذه القواعد تدل على الخلق القويم الذي يجمع بين الرقي والبساطة لهربة

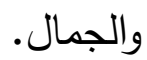

وتحتل ضوابط السلوك الاجتماعي " الاتيكيت " الجزء الأكبر من قواعد المراسم ويقصد بتلك الضوابط مجموعة العادات والتقالبد والتي تطورت في مختلف الدول، وبتكرار مراعاتها أصبح من المتفق عليه ضرورتها وفائدتها لحسن سير التعامل الرسمي أو الاجتماعي سواء في المجتمع الدولي أو المحلي.

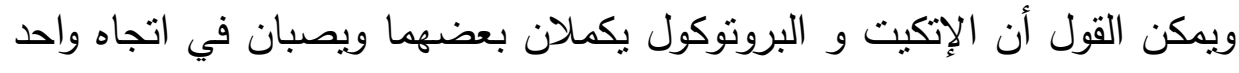
وهو التتاسق فإذا كان البرتوكول مجموعة من القواعد والإجراءات في العلاقات الرسمية الإنسانية، فإن الإتيكيت أو السلوك الحسن يصب في في العلاقات الخاصنة الفردية وعلى مستوى المجتمعات الصغيرة، ومع هذا يعتبر البروتوكول والإتيكيت 
د. محمد يوسف إبراهيم - -المنظور الإسلامي للاتكيث، ص: 94-65

مظهر من مظاهر السلطة شكلاً وموضوعاً فهو يقوي مع مركزية السلطة وفرديتها

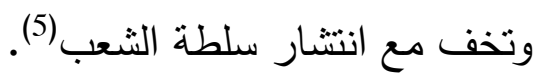
إن كلمة " إتكيت " كلمة فرنسية تعني البطاقة التي تلصق على طرد طرد أو زجاجة

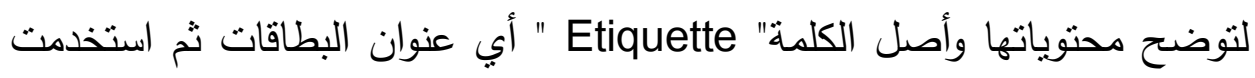
الكلمة للالالة على البطاقات التي كانت نوزع على المدعوين في القصور الملكية في فرنسا للتقيد بالتعليمات المدرجة عليها في حضرة الملك وكبار معاونيه (6). ويعرف الاتيكيت " Etiquette "بأنه فن الخصال الحميدة أو السلوك بالغ التهذيب فئسي

$$
\text { وتتعلق قواعده بآداب السلوك والأخلاق والصفات الحسنة (7). }
$$

وهومجموعة تصرفاتتؤدي إلى احترام النفس واحترام الآخرين وكل شخص لا يحترم نفسه ولا يجعل اعتبارا لقيمها لا يحق له ان يطلب من الآخرين اعتباره واحترامه،

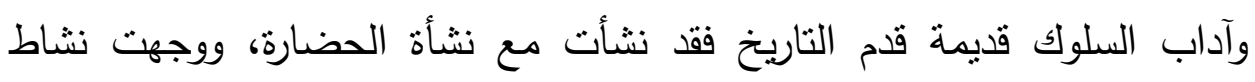

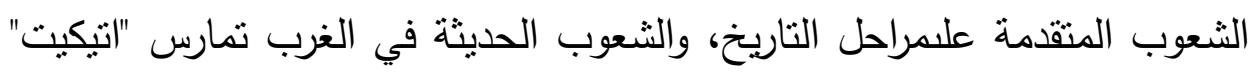
معينة تبرز من خلال معالم التهذيب والخطوط الأساسية التي تلتزم بها في حياتها

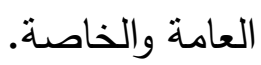

باختصار إن الإتيكيت هو : فن العيش بطريقةحضارية أو فن حُسْنِ النَصرُفِ بِكُلِ:

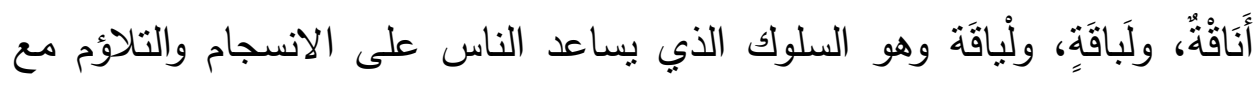

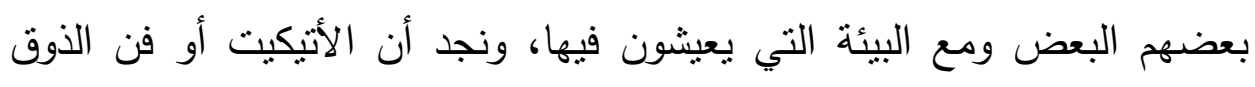

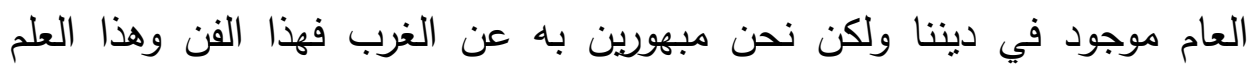

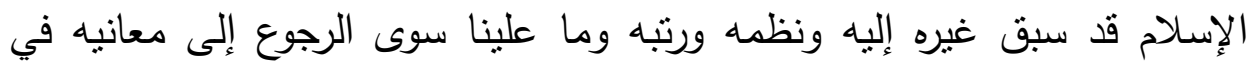

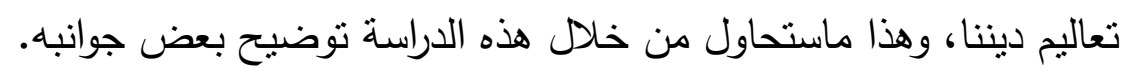
ثانياً: أهمية الإتكيت في الحياة المعاصرة: الإتيكيت سمة تتنتر كإحدى وسائل الضبط الاجتماعي بحيث تتظم العلاقات

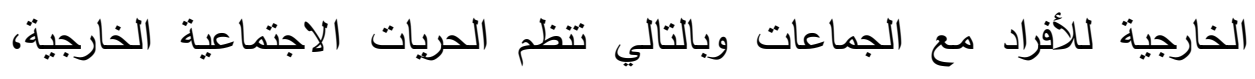


ويرتبط هذا المفهوم ارتباطاً وثيقاُ بالمجتمع الذي يسود فيه تتظيم تسلسلي، لذا فإن تحسين سلوك الإنسان والرقي به نحو السلوك والتصرف الحسن هو أحد أهم معاني

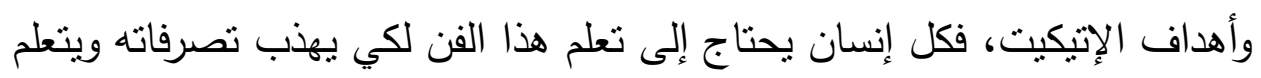

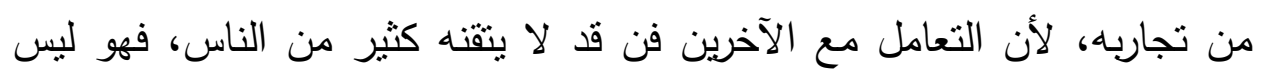

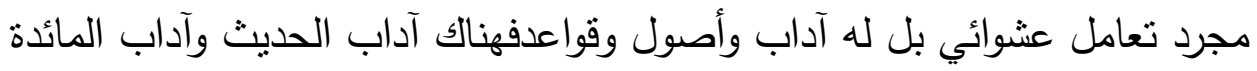

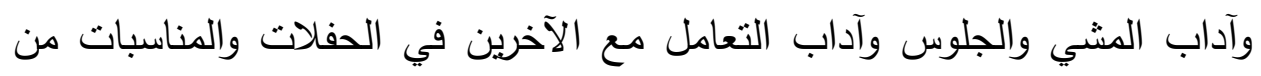
أفراح وأتراح وغيرها الكثير من الآداب والقواعد.

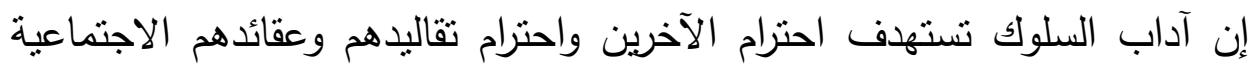
وهي معيار الإنسان المتحضر، ودليل على ثقافته ورفعة بيئته التي ينتمي إليها،

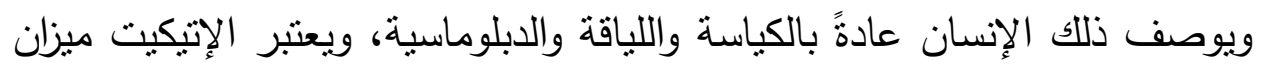

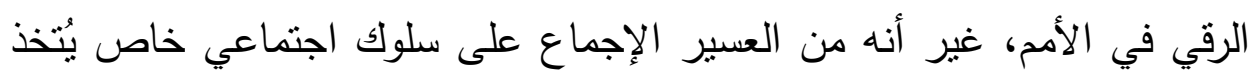

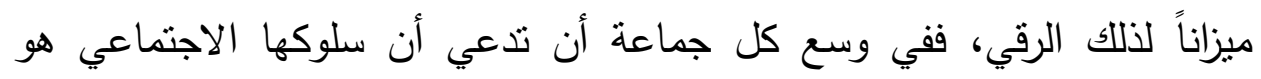

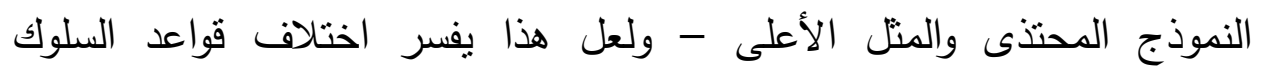
الاجتماعي باختلاف الجماعات والأمم واختلاف العصور - إلا أن هناك فضائل

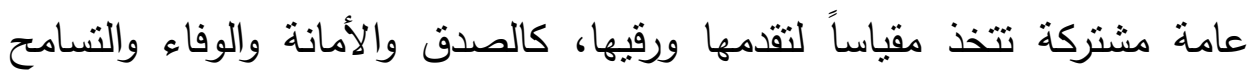

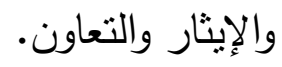
إن هذا الفن وهذا العلم الخاص بآداب السلوك هو ببساطة يساعد الناس على

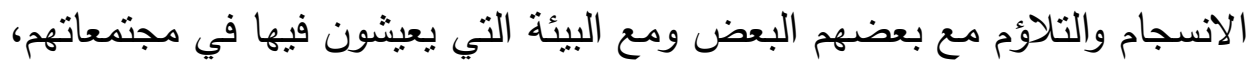

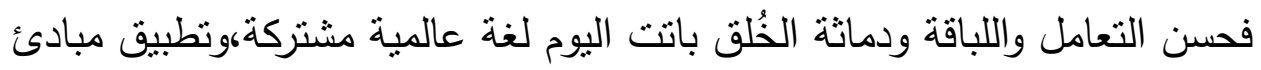

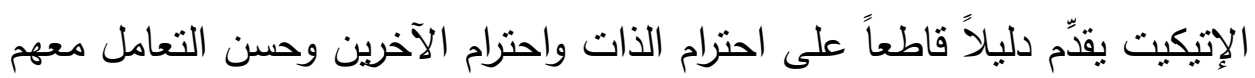

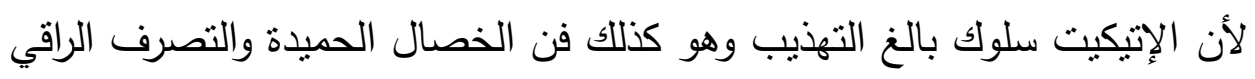

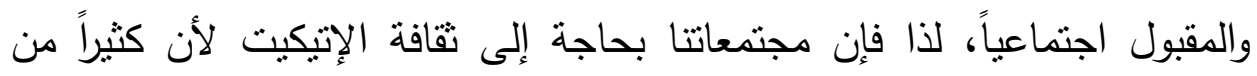
الأثخاص بفتقدها معتقداً أنها مجرد مظاهر براقة تقتصر على إنى ارتداء أفضل 
د. محمد يوسف إبراهيم - -المنظور الإسلامي للاتكيث، ص: 94-65

"الماركات" العالمية وركوب أحدث السيارات ومتابعة آخر صيحات " الموضة" والتفوه بكلمات إنجليزية أو فرنسية وأن نأكل بيدك اليسري وترقق صوتلك وغير ذلارتك من الانطباعات السطحية عن الإتكيت.

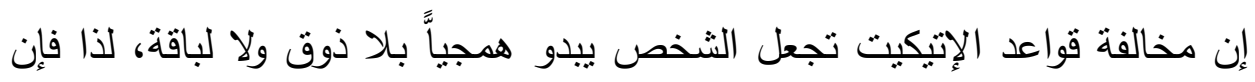
الالتزام بأصول وقواعد الإتيكيت في أي ظرف أو مكان يحمي صاحبه من هفوات لات هات

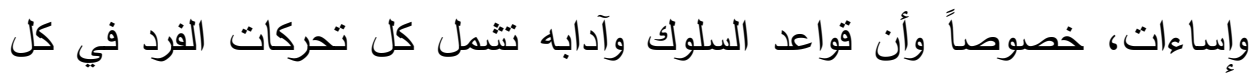
مجالات الحياة، ومع ذلك يمكن الخروج في بعض الحالات عن قواعد الإتيكيت في

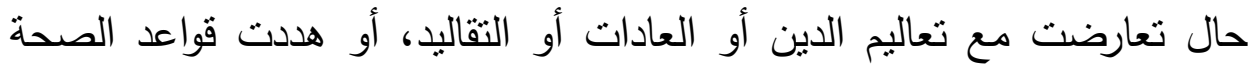

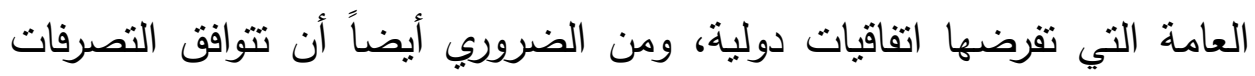

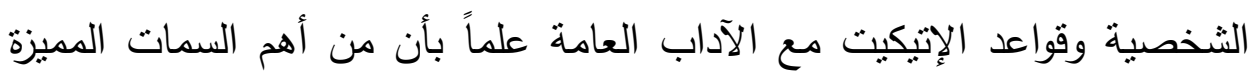

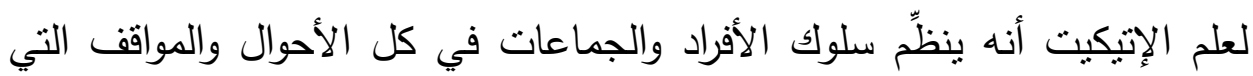
تواجهمه.

\section{ثالثثاً: أهمية الإتكيت في الإسلام:} قد يظن البعض أن الإتيكيث هو أحد مظاهر الحضارة الغربية، قد وصلتنا من الإسلان

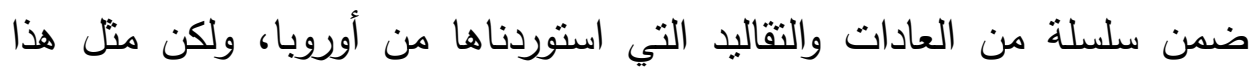

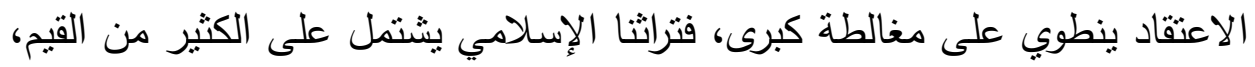

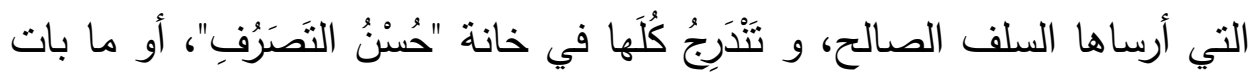
يُعْرَفُ بالإتيكيت الهيا

و إذا كان ما وصلنا من الغرب عن الإتيكيت يَقْتَصِر على المظاهر دون غيرها،

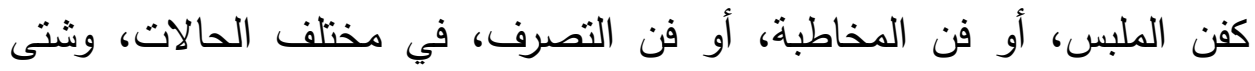
المناسبات، ككيفية تتاول الطعام، أو المشي، أو الجلوس، فإن ما حفل به تراثنا

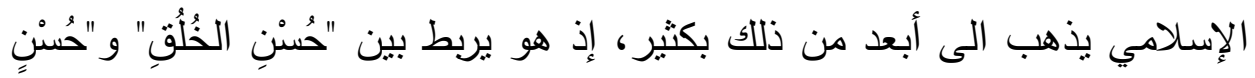

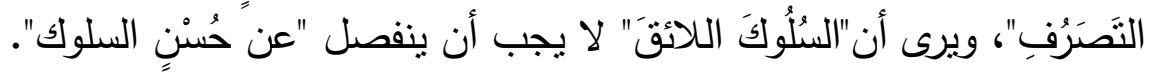


وتمنل القيم الخلقية جانباً كبيراً من حباة الإنسان الروحية، ويقاس الإنسان وفق المعايير الظاهرة بالتزامه جانب الأخلاق السامية، كما تقاس المجتمعات بسمو الهان

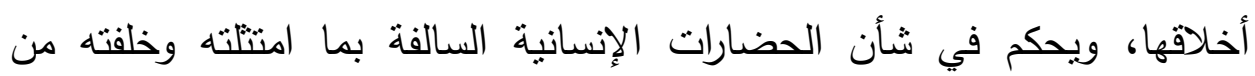
مقاييس الأخلاق العليا(8).

وللأخلاق دور عظيم في حياة الأفراد والمجتمعات والأمم ولذلك نجد ذكرها في كآفة الكتب الإلهية السابقة، ونجد العناية الثديدة بها في الكتاب المهيمن عليها وهو القرآن الكريم وذللك لارتباطها بصلاح أمر الناس وكذللك لدورها في نشر بهابه الفضيلة واستقامة السلوك (9). إن تراثنا الإسلامي يعتبر أن الآداب العامة، ليست سوى' "مظها" للأخلاق الحميدة،

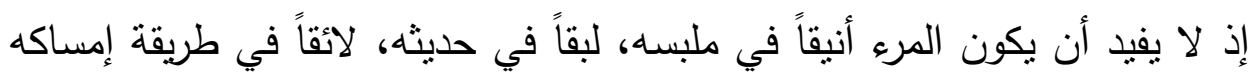

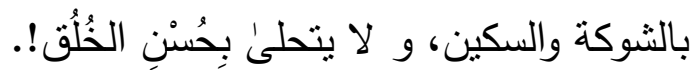

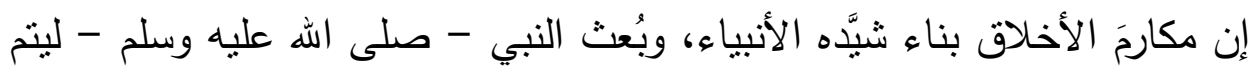
هذا البناء، فيكتمل صرح مكارم الأخلاق ببِعثثه - ((إنما بُعثت لألمحَ مكارم

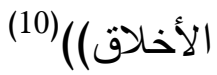

"والناظر في هذه العقيدة، كالناظر في سيرة رسولها، يجد العنصر الأخلاقي بارزا

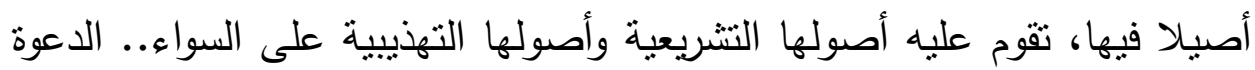
الكبرى في هذه العقبدة إلى الطهارة والنظافة والأمانة والصدق والعدل والرحمة والبر وحفظ العهد، ومطابقة القول للفعل، ومطابقتهما معا للنية والضمير والنهي عن

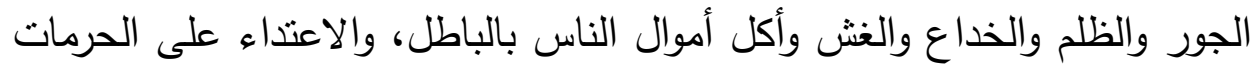

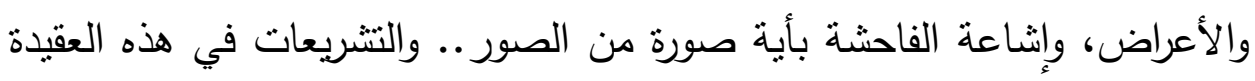

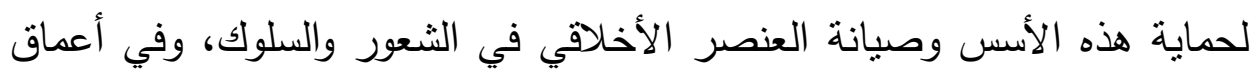

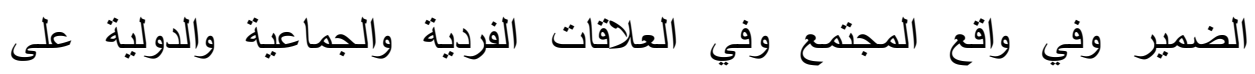


د. محمد يوسف إبراهيم - -المنظور الإسلامي للاتكيث، ص: 94-65

لم يعُدِ الإسلام الخلق سلوكًا مجرَّدًا، بل عده عبادةً يؤجر عليها الإنسان، ومجالاً

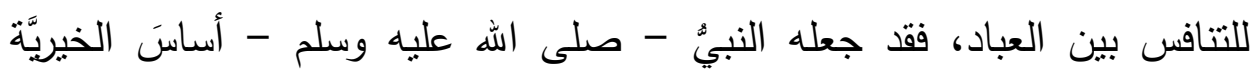

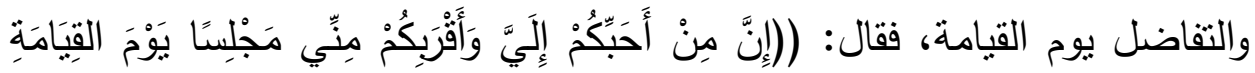

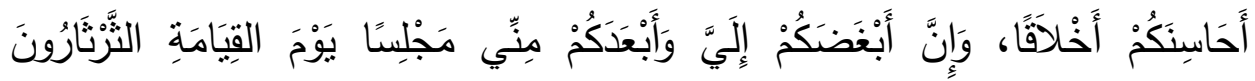

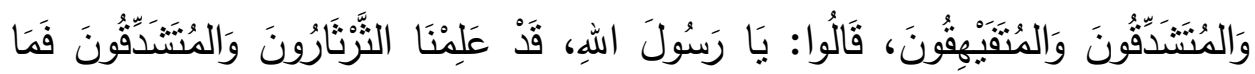

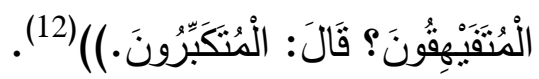

وكذلك جعَل أجر حُسن الخُلق ثقيلاً في الميزان، بل لا شيء أنقلُ منه، فقي

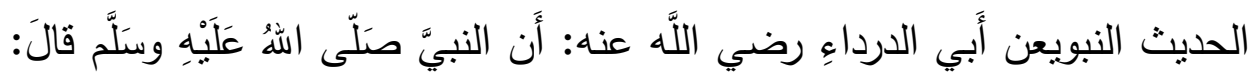

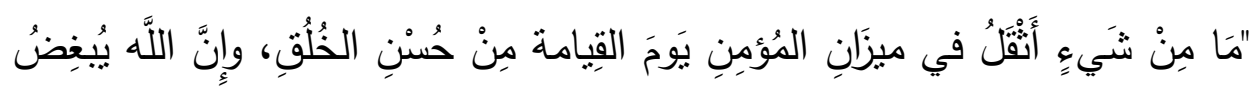
الفَاحِشَ البََِيِّ "(13). وجعَل كذلك أجرَ حُسن الخُلق كأجرِ العبادات الأساسية، مِن صيام وقيام، فقال:

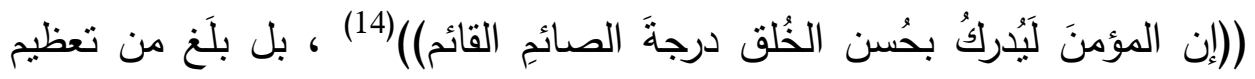

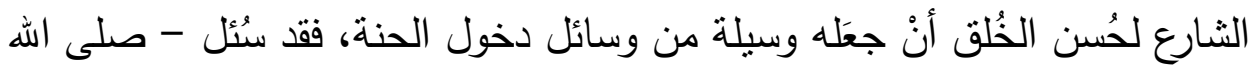

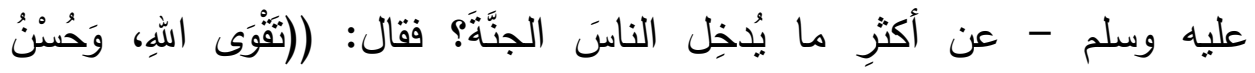

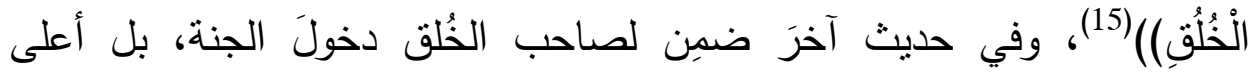

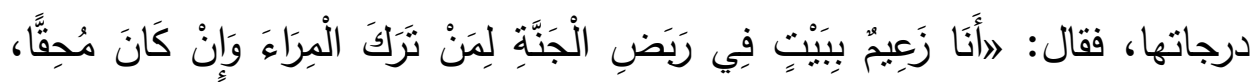

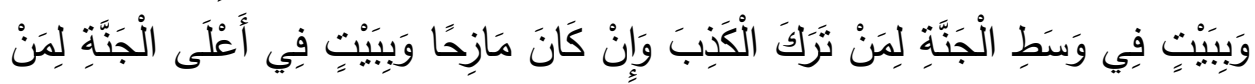

حَسَّنَ خُلُقَهَهُ

وأهنم الإسلام منذ عهد النبوة والخلافة الراندة بتكريس آداب التعامل بين الناس على أساس البر والمعروف والتراحم والترابط والتكامل والمساواة والتواضع، وشملت لهن

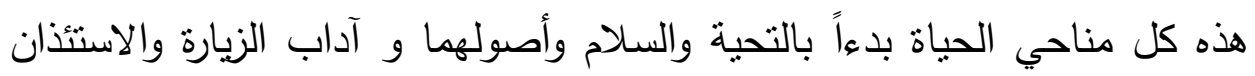
المسبق وآداب المائدة وآداب الضيافة وحتى آداب التعامل والمعاشرة فيما بين الفرد وأهل بيته وفيما بينه وبين الآخرين. 
إن من أهم ماينبغى أن يعرفه المسلم الأخلاق الإسلامية الجامعة التي لايستكمل

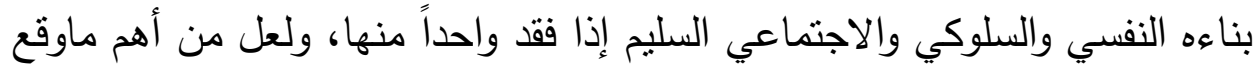
التفريط به من قبل المسلمين هو هذا، فقد ضخم بعضهم خلقاً من أخلاق الإسلام

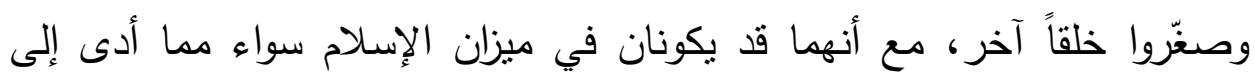

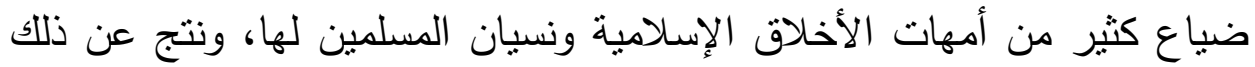
أن فقدت الثخصية الإسلامية جمالها وكمالها وتتاسق سلوكها وتكامله (17. 


\section{د. محمد يوسف إبراهيم - -المنظور الإسلامي للاتكيث، ص: 94-65}

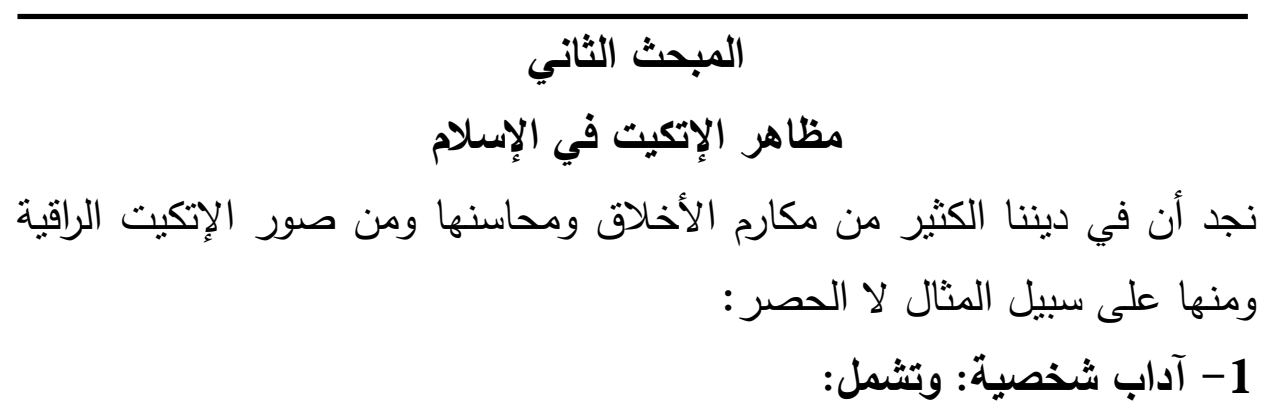

أ/ التحية:مصدر الفعل حياه يحيه، تحية ومعناها في اللغة: الدعاء بالحياة فيقال حياك اله أي أبقاك ثم توسع وشمل إطلاق التحية على كل ماهو في معناها من

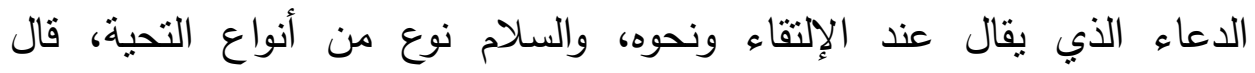

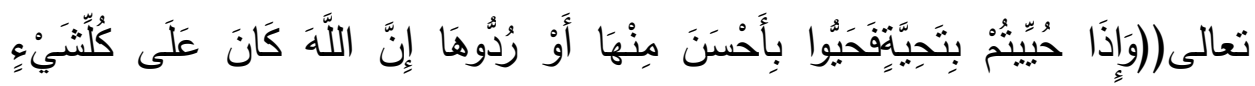

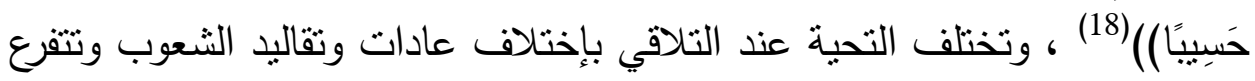
عبارات التحايا منل:صباح الخير - مساء الخير - أهلا وسهلا - نهارك سعيد

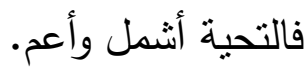
والسلام هو تحية الإسلام الذي خص الله تعالى به الأمة الإسلامية وميزها به عن

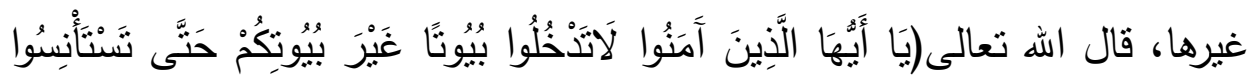

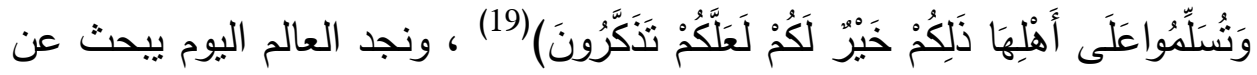

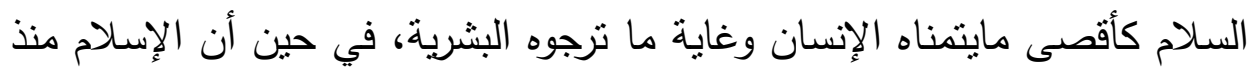

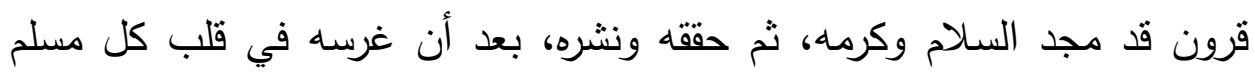

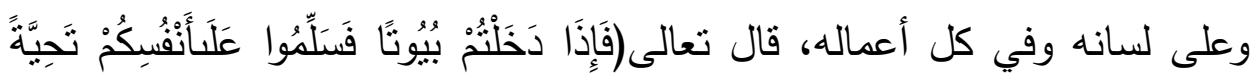

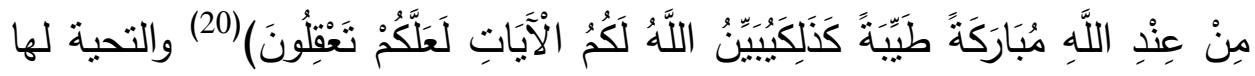
أداب كثيرة في الإسلام منها إستصحاب بشاشة الوجه ولين الجانب وحرارة اللقاء

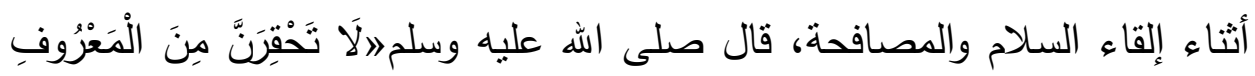

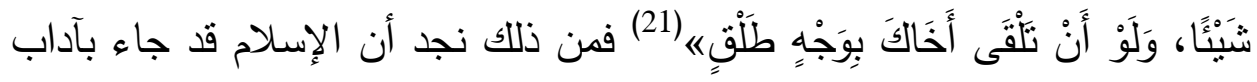

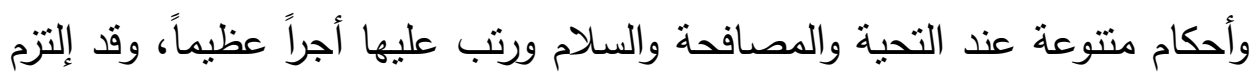


بها الصحابة والتابعين، وسطروا فيها نماذج رائعة لخلق وسلوك المسلم، وصيغة السلام هي"السلام عليكم ورحمة الله وبركاته" هذا أكملها وأقلها"السلام عليكم". ب/حسن الحديث وحسن الإصغاء:

يعتبر اللسان سيد الأعضاء ومن مهمات اللسان الكثيرة التعبير عن حاجات النفس اهن وإيصال المعلومات إلي الغير عن طريق النطق والكلام وفي الحديث (عَنْ أَبِي

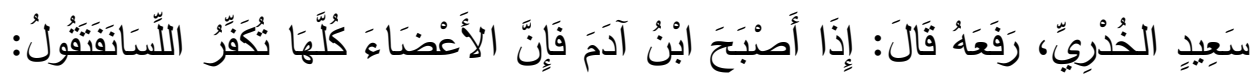

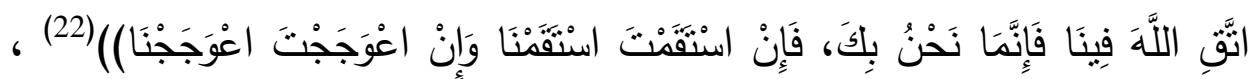

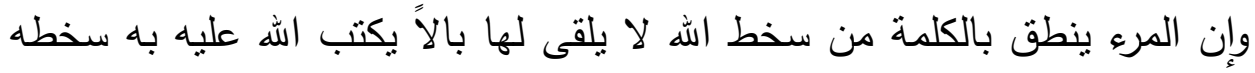

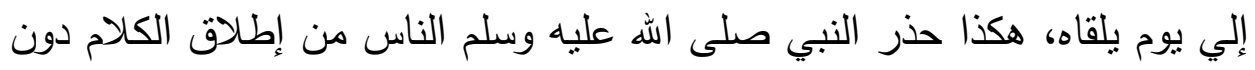
النظر في العواقب فعدم ضبط اللسان يؤدي إلي المهالك قال تعالى((أَلْمَ نَجْعَلْ

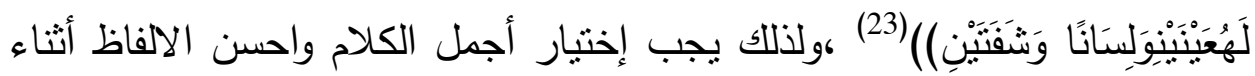

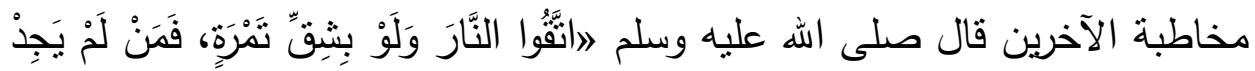

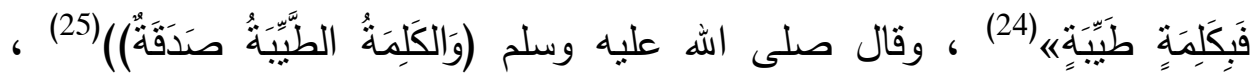
وأيضاً يجب الهدوء والإبتسام أثناء الكلام وعدم التجهم والعبوس في وجوه الآخرين

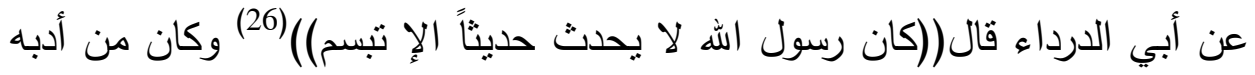

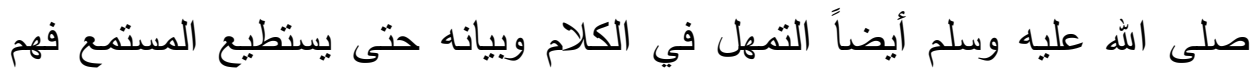
المراد ومن هذا الحديث عن عائثة رضى اله عنها قالت((ماكان رسول اله يسرد

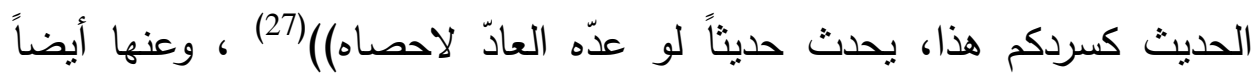
قالت((كان كلام رسول الله كلام فصلا يفهمه كل من سمعه)(28) ، وأن النبي صلى اله عليه وسلم كان إذا تكلم بكلمة اعادها ثلاثاً حتى تقهم عنه. ومن ذلك أيضاً خفض الصوت وعدم رفعه أكثر من الحاجة وتجنب الصراخ إنهان

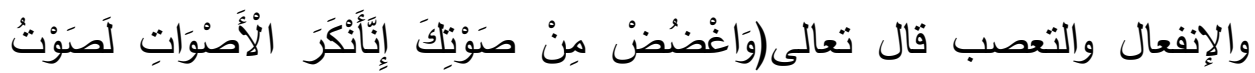
الْحَمِيرِ) (29) ، ومن ذلك جاء التوجيه الرباني للمؤمنين بالتأدب مع رسول صلى الله 
د. محمد يوسف إبراهيم - -المنظور الإسلامي للاتكيث، ص: 94-65

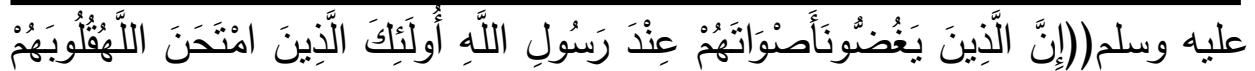

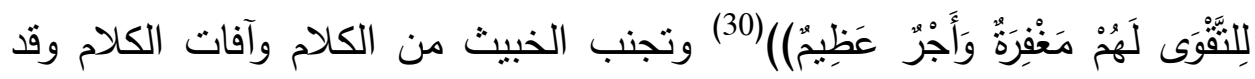

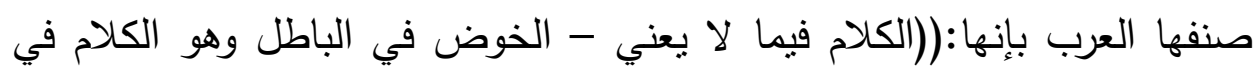
المعاصي - الفحش والسب والبذاءة- السخرية والإستهزاء - الغيبة والنميمة - كلام

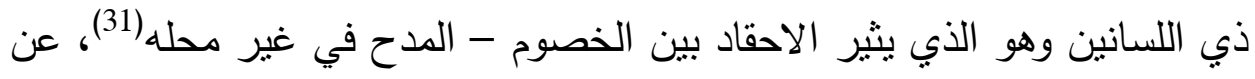

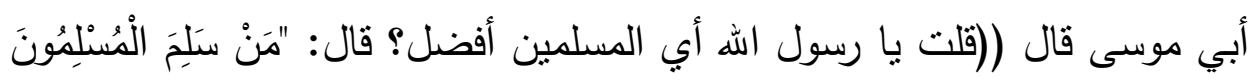

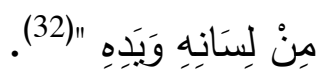

والإستماع وسيلة مكملة لفن الحوار، فالحديث أخذ وعطاء والإنصات مهارة لحوار

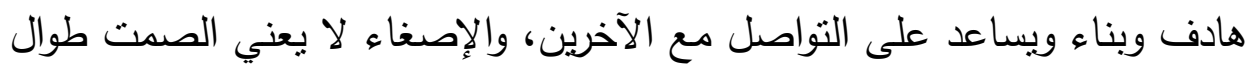

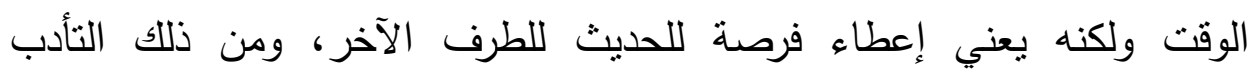

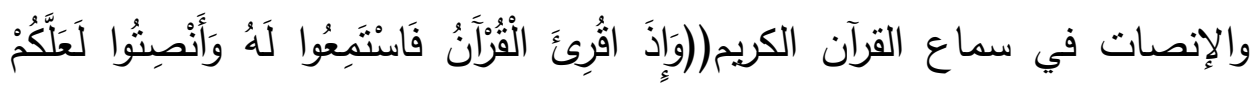

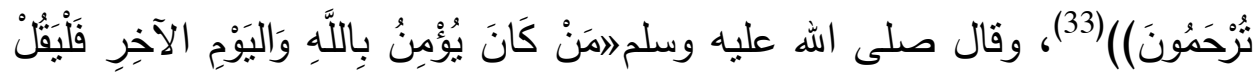

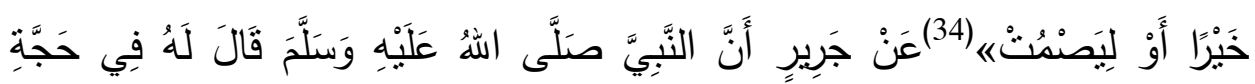

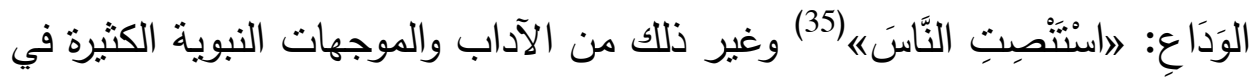
هذا المجال. ج/احترام الوقت: الوقت هو الحياة فعمر الإنسان عبارة عن أيام والأيام عبارة عن ساعات ودقائق،

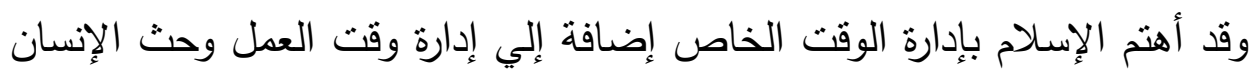

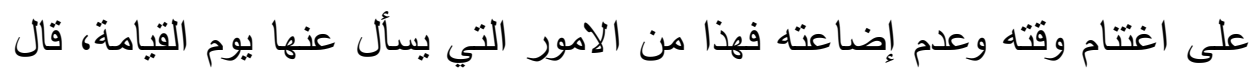

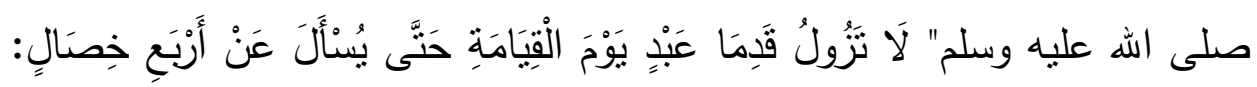

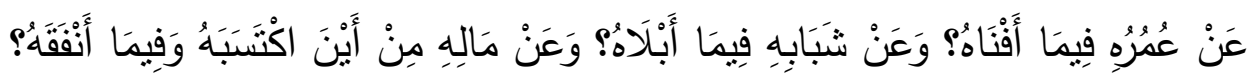

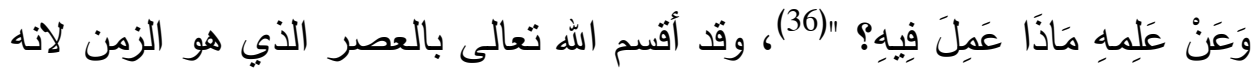

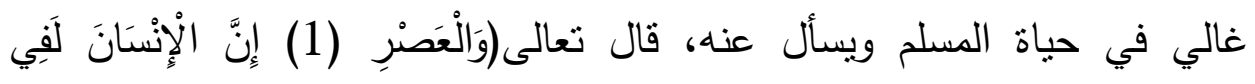


خُسْرِ)(37) ، كذلك فقد أقسم الله تعالى ببعض الاوقات في آيات كثيرة منها قوله

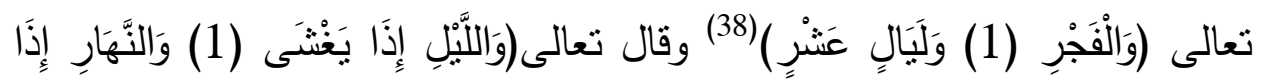

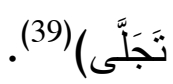

وإدارة الوقت وتنظيمه الطريق الاول في رقي الثعوب وتقدمها وإحترامها لمبادئها وقيمها ونجاحها، وما يميز الدول المتقدمة عن دولنا هو الإلتزام والإحترام للوقت

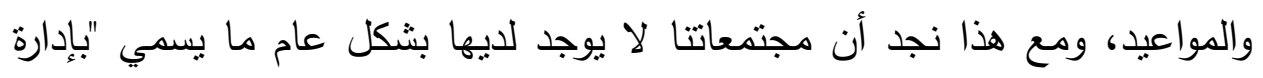

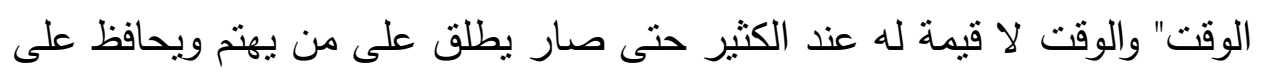

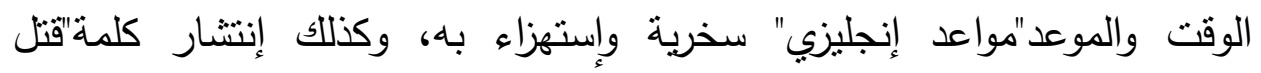
الوقت"الإجبار الثخص على الجلوس وإضاعة الوقت وقتله فعلاً.

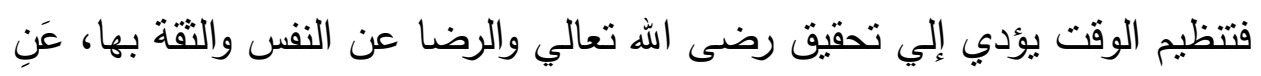

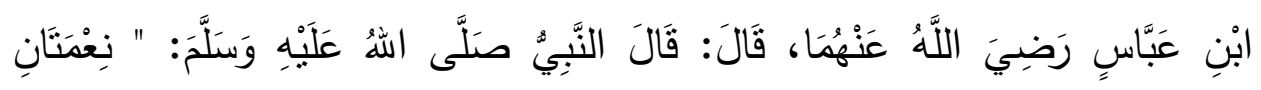

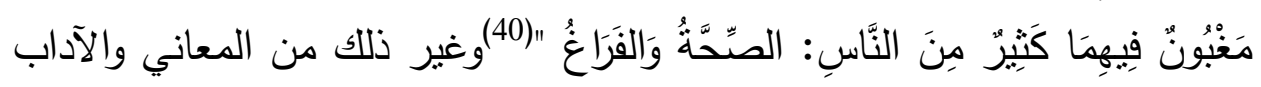
الكثيرة في الوقت. د/الاهتمام بالملبس:

اللباس نعمة من الله تعالى خص بها الإنسان دون غيره من المخلوقات ليستر بها

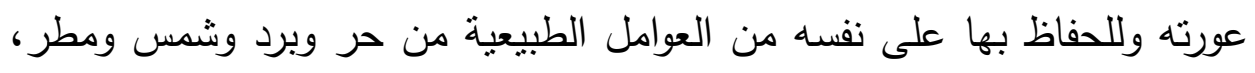

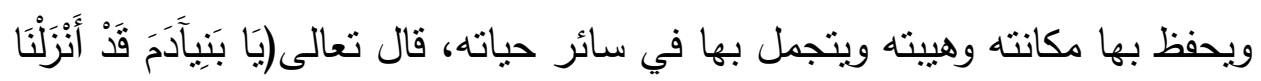

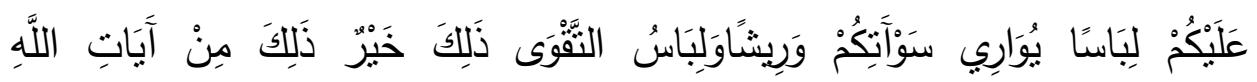

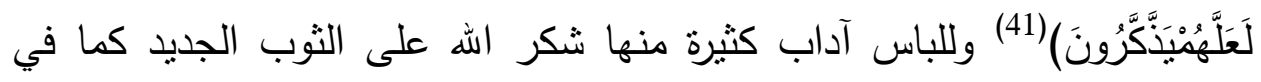

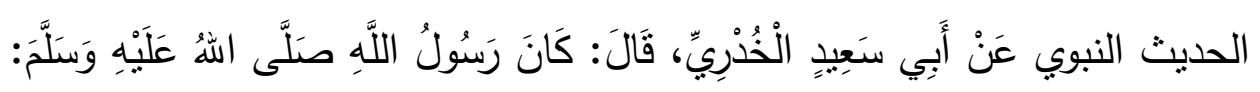

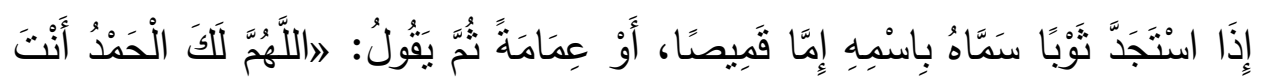

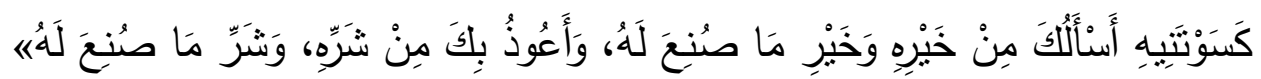

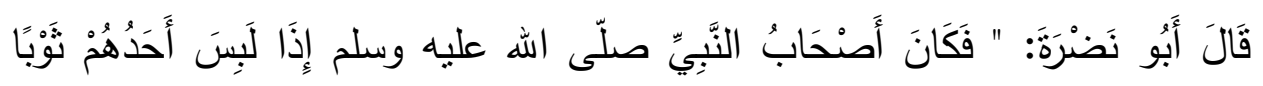


د. محمد يوسف إبراهيم - -المنظور الإسلامي للاتكيث، ص: 94-65

جَدِيدًا قِيَلَ لَهُ: تُبْلَى وَيُخْلِفُ اللَّهُ نَعَالَّى "(42)، ونظظافة الملابس والمحافظة على الرائحة الطيبة والتوسط وعدم التفاخر والتباهي ومناسبة الملبس لسن المره ومكانته وتقاليد المجتمع والنهي عن لبس الحرير كما في الحديث النبوي عَنْ ثَابِتٍ، قَالَّ

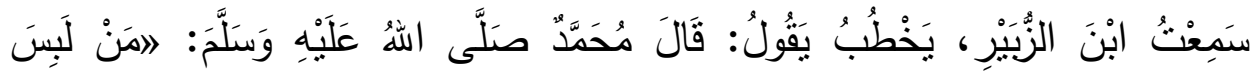

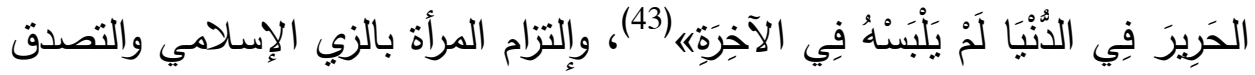
بالملابس القديمة وغير ذلك من الآداب الكثيرة في هذا الجانب.

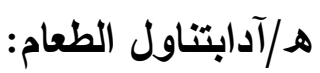

لا يستغني الإنسان عن الطعام والثراب في حياته، والمسلم يجعل كل حياته وأفعاله طاعة وعبادة لله تعالى، فهو لا ينظر إلي الطعام والثراب على أنها هدف وغاية

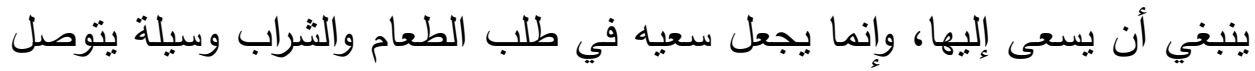
بها إلي الحفاظ على حياته والتقوي على عبادة الله تعالى.

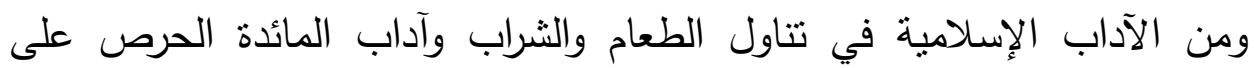

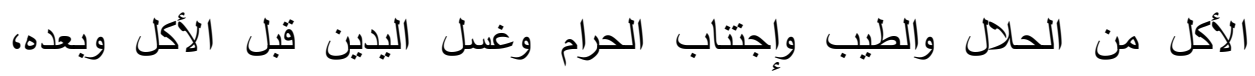

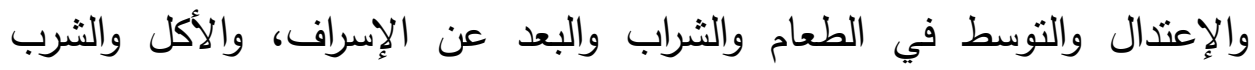

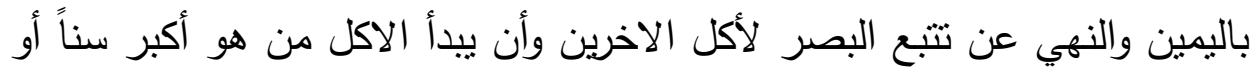

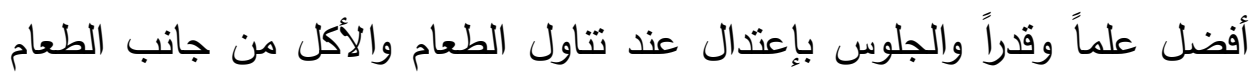
ومما يلي الأكل وتجنب الأكل من وسط الطعام لحديث النبي صلى الله اله عليه

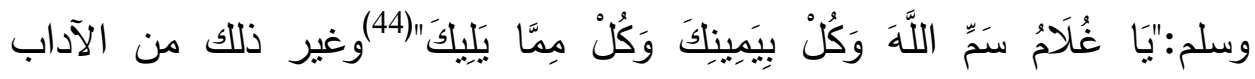
والموجهات النبوية المباشرة في هذا الجانب.

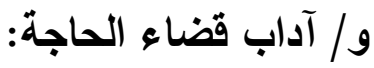
لم يدع الإسلام في حياة المسلم شيئاً الاّ وحرص على أن يبينه ويفصل فيه بما

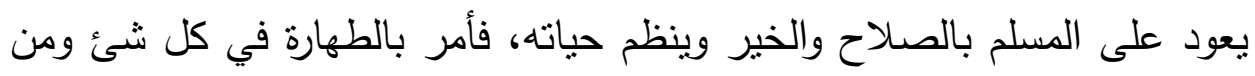

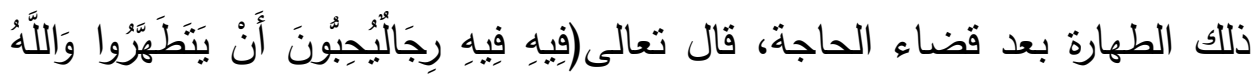


يُحِبُّ الُُْطَِّّرِينَ)(45) ، ومن الآداب الإسلامية التي يحرص عليها المسلم عند قضاء الحاجة تحري المكان المخصص لذلك فالمسلم لا يقضي حاجته أو يتبول

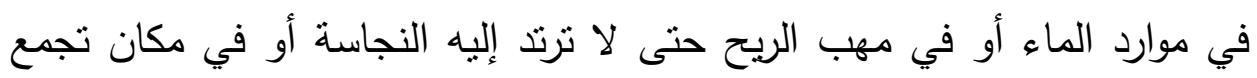

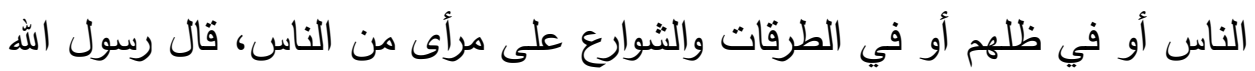

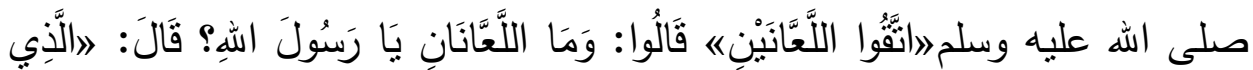

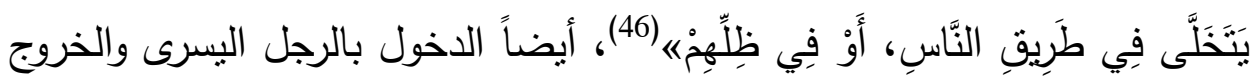

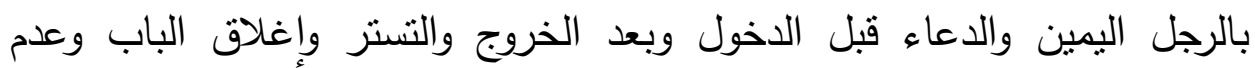
إصطحاب شيء فيه ذكر الله وغير ذلك من الآداب الكثيرة في هذا الجانب.

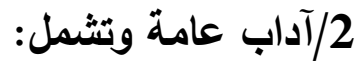

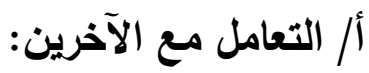
الإنسان إجتماعي بطبعه وغرائزه والميل إلي الحياة الإجتماعية ومخالطة الاخرين أمر ضروري وقد تختلف طبائعهم وعاداتهم وتقاليدهم وعقائدهم، لذا يتوجب عليه الإلتزام بالآداب العامة التي يسنطيع من خلالها التعايش مع الآخرين في ودومحبة، والقاعدة الذهبية في هذا التعامل"عامل الاخرين بما تحب ان يعاملوك به" وهذا

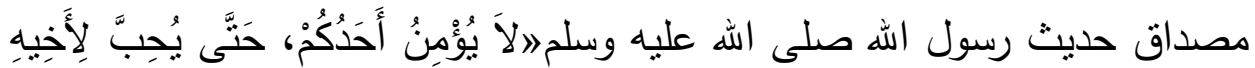

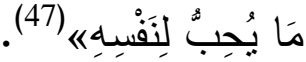

ونجد ان الإسلام قد وضع قواعد وآداب عدة للتعامل بين الناس ومنها: الإخلاص لله تعالى وحسن الخلق، التسامح والعفو وقبول العذر، لين الجانب والتواضع، التأدب وحسن الإستماع والإنصات، الصدق والوفاء وترك المعصية والغضب وإلتزام الهدوء، الدقة في المواعيد وعدم إخلاف الوعد، إحترام مشاعرالآخرين والإحسان إليهم، والمحافظة على كرامتهم والثكر على المعروف

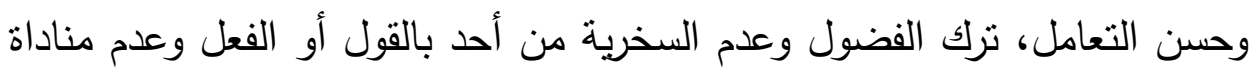


د. محمد يوسف إبراهيم - -المنظور الإسلامي للاتكيث، ص: 94-65

أحد بلقب يكرهه، الإهنمام بالآخرين وغير ذللك من الكثير من الموجهات والآداب في هذا الثنأن.

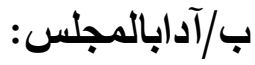

تقتضي ظروف الحياة للإنسان في حياته اليومية مجالسة ومخالطة الآخرين في مجالس عامة أو خاصة كمجالس العلم ومجالس رجال الدين ورجال السياسة والزبارات، ولكل من هذه المجالس آداب وتقالبد يتعارف عليها الناس، وقد وضع الإسلام لهذه المجالس أعرافاً وآداب تميزها عن غيرها من المجالس ومن هذه الآداب:

السلام عند الدخول للمجالس وعند الخروج منها، الجلوس حيث ينتهي جلوس الاخرين، المشاركة في مجالس الخير وتجنب مجالس السوء، التيامن في الدخول للمجلس والخروج منه، الإفساح في المجالس وعدم التفريق بين الجالسين، تجنب نقل أحاديث وأسرار المجالس، ومنع التتاجي مع البعض دون الآخرين وغير ذلك. ج/آداب الإستئذان: هو من القضايا الإجتماعية المهمة التي تراعي خصوصيات الفرد والجماعة، فهو خلق رفيع يدل على حسن أدب وحياء صاحبه ونزاهة النفس ومنها روئة ما لا يجب أن يراه عليه الغير أو أن يسمع حديثاً دون معرفة ودراية المتحدثني أو الاخول على قوم وإيقاعهم بالمفاجأة أو الحرج والإستئذان هو طلب الأذن ويكون لاخول بيت أو الاخول إلي مجلس أو الخروج منه،أو التصرف في مناع وحق الغير ، أو إبداء رأي فيما يتعلق بالغير أو سماع حديث الآخرين. وقد نهي الإسلام أن يدخل الثخص بيت غيره دون إسنثذان، وهناك مجموعة من الآداب التي وصى بها الإسلام في قضية الإسنثئان منها:

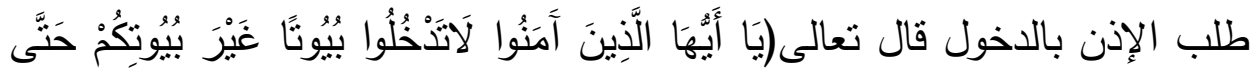

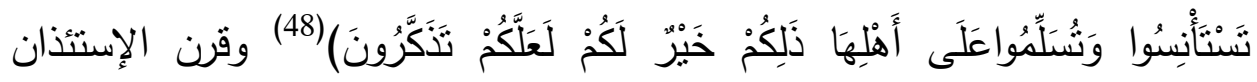


بالسلام وتكرار الإستئذان ليكون ثلاثاً وطلب الإستئذان في البيت الواحد بين الأهل عند الدخول على غرفة أحدهم وتعليم الاطفال والخدم أداب الإستثئان.

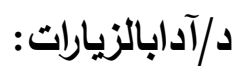

الزيارة سلوك إجتماعي مميز وواجب يعزز العلاقات والإلفة والمودة والتقارب بين

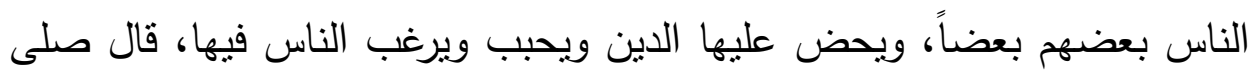

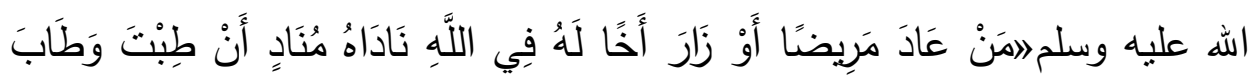

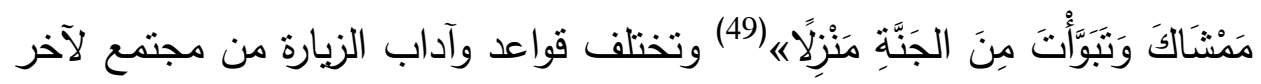
حسب العادات والتقاليد التي تسود ذللك المجتمع أي أن إحترام وتقدير الآخرين

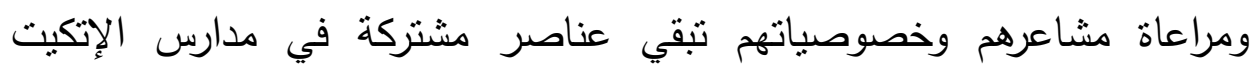

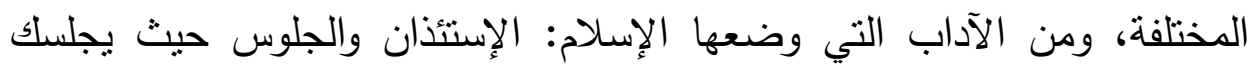

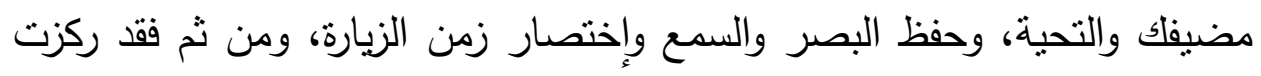

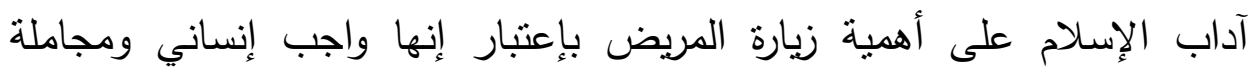

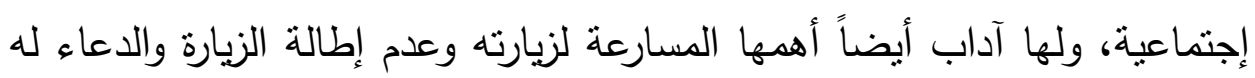

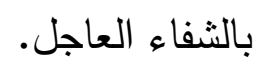

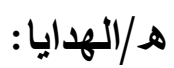

الهدية كما عرفها أهل العلم هي عطية بلا اثتراط مقابل وهي تعبير عن مشاعر لا

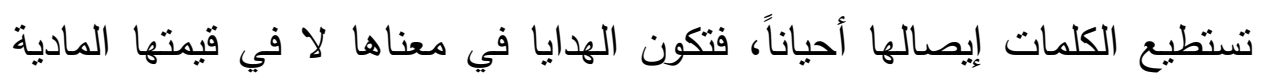
فهي تعبير محسوس عن الحب والمودة بين القلوب، قال رسول الله صلى الله عليه

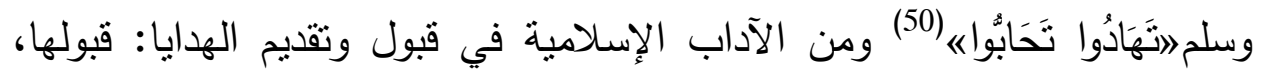

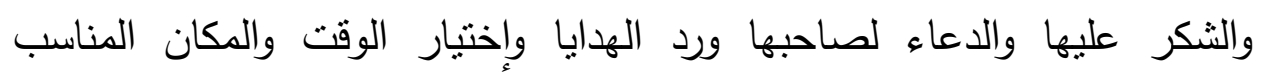
لتقديمها وتخصيص الأقربون بالهايا وغير ذلك. 


\section{د. محمد يوسف إبراهيم - -المنظور الإسلامي للاتكيت، ص: 94-65}

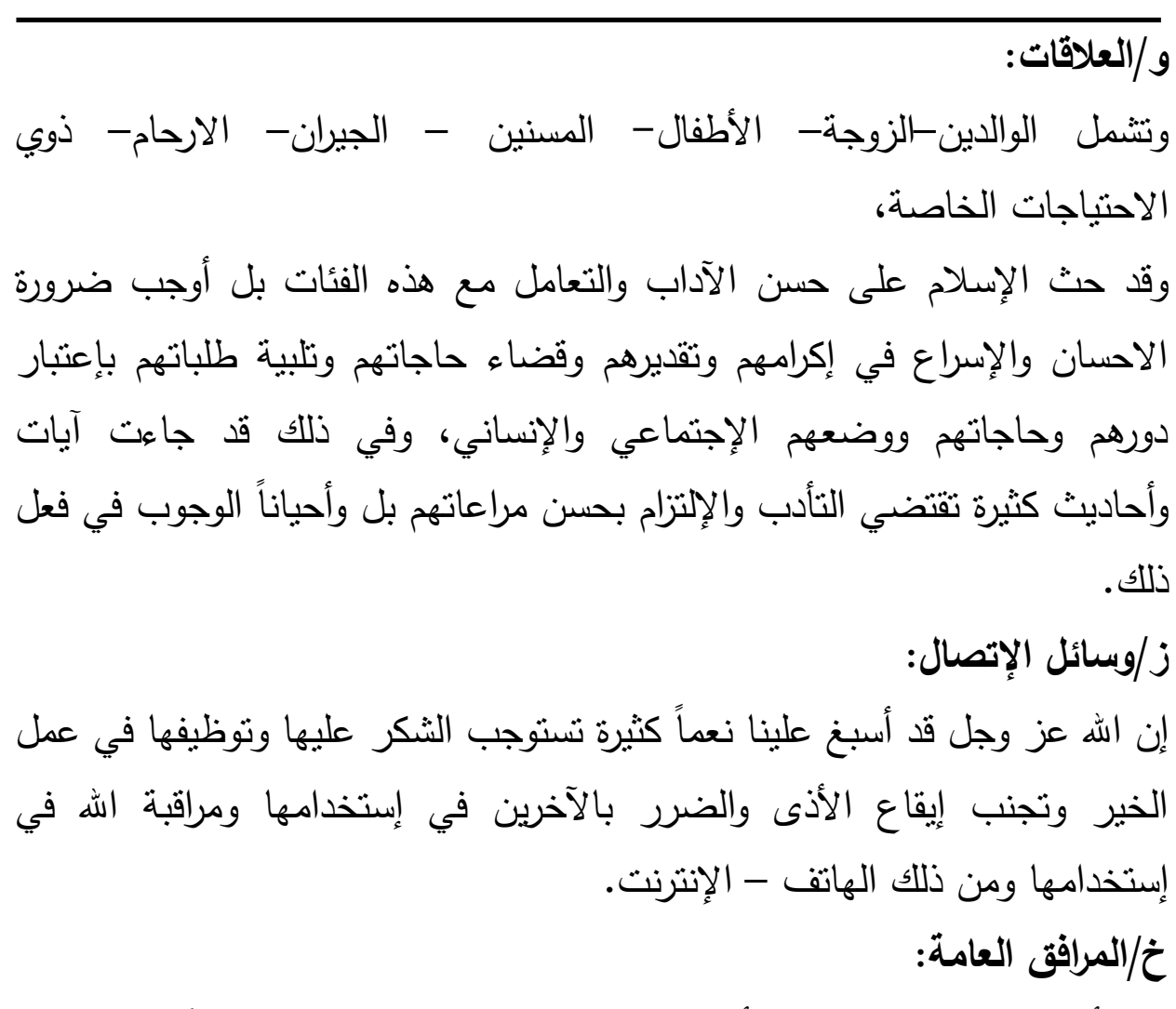
كما أهتم الإنسام بالفرد فقد أهتم بالمجتمع ومؤسساته ومن ذلك الأماكن العامة

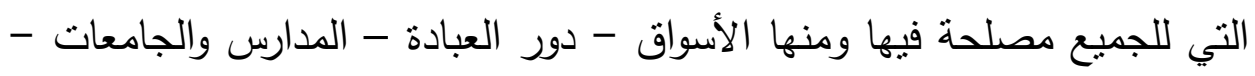

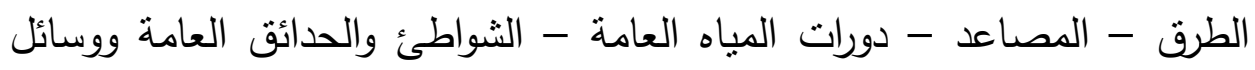

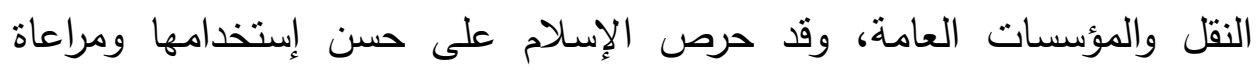

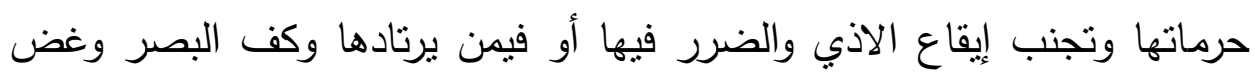

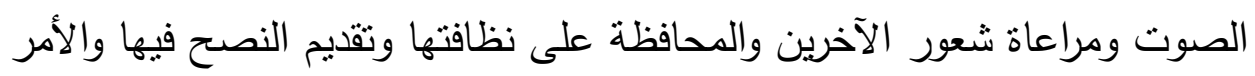

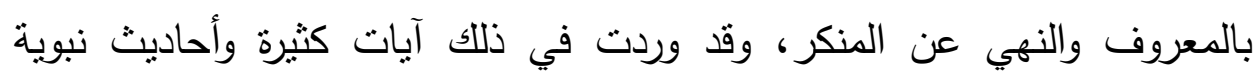
عظيمة وهي تحمل آداب وموجهات جليلة يجب على المسلمين الإلتزام بها والعمل على التقيد بها وتتفيذها. 
1- الإتكيت في حياة الناس أمر ضروري ومستمر باستمرار الحياة باعتبار طبيعة

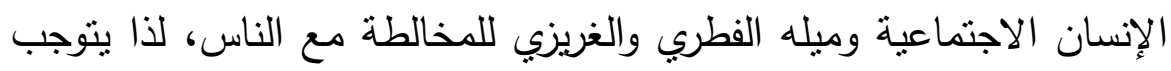

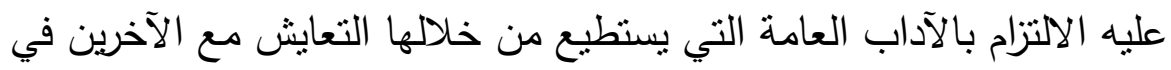

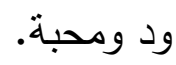

2- الإتكيت في الأصل خلق إسلامي أصيل كان معلمه أفضل الخلق وخير البشرية، وكان يتعامل مع الناس بقدرات ومهارات أخلاقية عالية ملك بهان الإنها

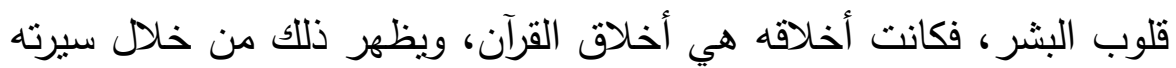
وسنته النبوية التي أسست لأفضل الأخلاق في تاريخ البشرية. 3- خلق المسلم وآدابه آداب ربانية مصدرها الوحي، ولذلك فهي قيم ثابتة ومنل عليا تصلح لكل إنسان بصرف النظر عن جنسه وزمانه ومكانه.

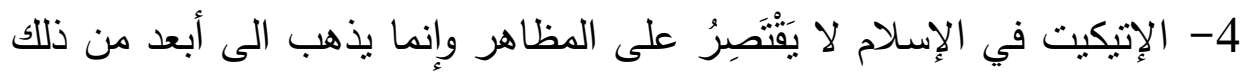

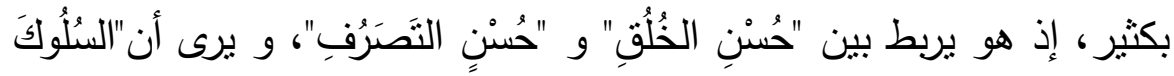

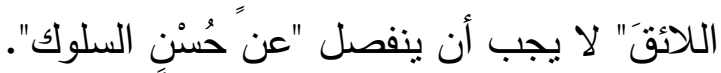

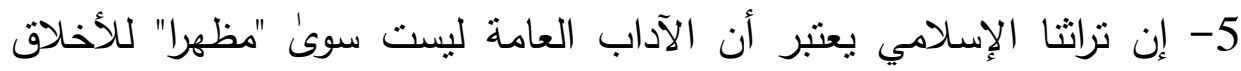

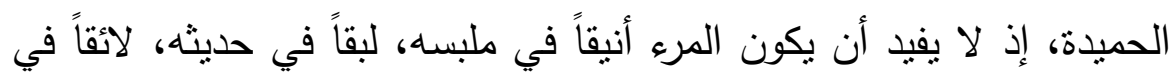

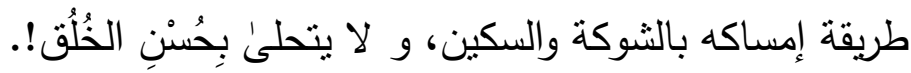

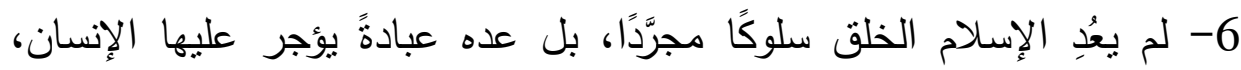

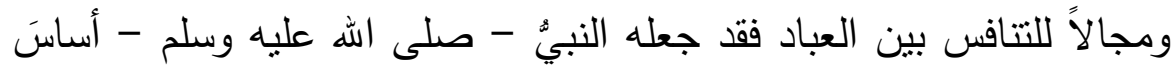
الخيريَّة والتفاضل يوم القيامة. 7- أهتم الإسلام بتكريس آداب التعامل بين الناس على أساس البر والمعروف والتزاحم والتزابط والتكامل والمساواة والتواضع، وشملت هذه كل البه مناحي الحياة بدءاً بالتحية والسلام وأصولهما و وآداب الزيارة والاستئذان المسبق وآداب 
د. محمد يوسف إبراهيم - -المنظور الإسلامي للاتكيث، ص: 94-65

المائدة وآداب الضيافة وحتى آداب التعامل والمعاشرة فيما بين الفرد وأهل بيته وفيما بينه وبين الآخرين.

8- يحتل العنصر الأخلاقي مكاناً بارزا أصيلا في الإسلام تقوم عليه أصولها التشريعية وأصولها التهذيبية على السواءهوتأتي التشريعات في الإسلاملحماية هذه الأسس وصبانة العنصر الأخلاقي في الثعور والسلوك، وفي أعماق الضمير وفي واقع المجتمع وفي العلاقات الفردية والجماعية والدولية على السواء.

9- إن من أهم ماينبغى أن يعرفه المسلم أن الإتكيت يرتبط بالأخلاق الإسلامية

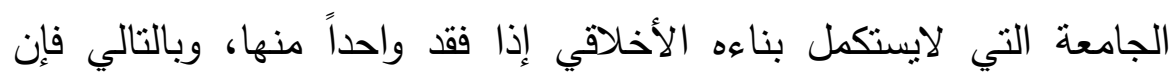
التقصير في بعض جوانب الإتكيت يكون تقصيراً في الجوانب الأخلاقية المرتبطة به.

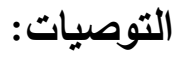

1- على كل مسلم أن يتخلق بخلق الإسلام وآداب السلوك المهذب أينما وجد، وأن لايكون سبياً في تشويه صورة الإسلام بتصرفات غير لائقة خارج بلده أو داخلهاأو حتى داخل بيته نفسه، باعتبار أن ممارسة ذلك عبادة يثاب عليها. 2- يجب الالمام بأصول الإتكيت باعتبارها ضرورة عصرية وعبادة اسلامية، لذا يجب الحرص على أن تكون جزءا أساسياً من ثقافتنا اليومية ومعاملاتتا الحياتية، والاّ تتفصل عن خلق المسلم وتربيته.

3- أهمية أن يكون للأسرة الدور الأعظد في تربية الأبناء على احترام الذات واحترام الآخرين وحسن التعامل معهم، وتربيتهم على الإحسان للأهل والأقارب والجيران واحترام المسنين وذوي الاحتياجات الخاصة. 4- ضرورة أن يكون لوسائل الإعلام والتوجيه دوراً واضحاً في ترسيخ القناعات بأهمية الإتكيت في مجتمعاتتا وتحبييه للناس بكل أسلوب من أساليب التأثير 
والبيان كالدراما والمسرحية والمجلة والكتاب والسينما والنكتة والكاريكاتير وغير ذللك من الأساليب.

5- أهمية تضمين مادة الإتكيت ضمن المناهج التعليمية في رياض الأطفال

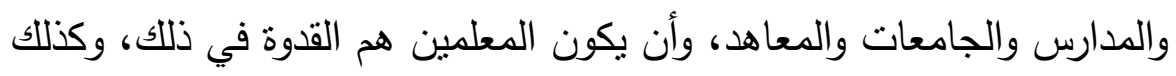
استصحاب الدور الحيوى والمؤثز للمساجد والمؤسسات الدينية الأخرى في لهني ترسيخ دور ورسالة الإتكيت في المجتمع. 6- على الدولة ومؤسسات المجتمع العمل على حماية الآداب والتقاليد الرفيعة

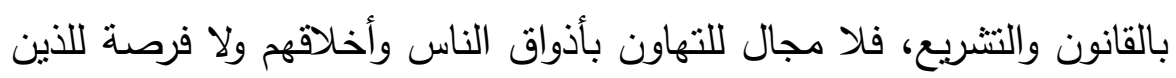

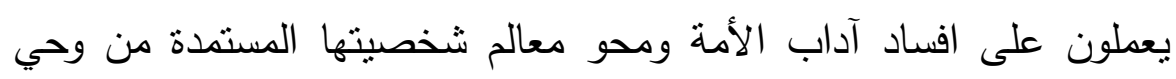

$$
\text { ربها وشريعة رسولها. }
$$

7- أهمية قيام الدولة ومؤسسات المجتمع بترقية المضمون والذوق وخاصة فيما

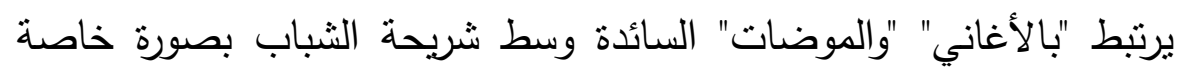

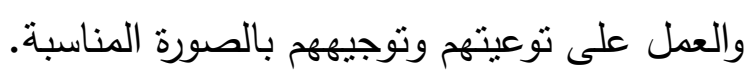


د. محمد يوسف إبراهيم - -المنظور الإسلامي للاتكيث، ص: 94-65

\section{خاتمة:}

مما سبق يتبين مدى أهمية ودور الإتكيت باعتبار ارتباطه بأخلاق وآداب

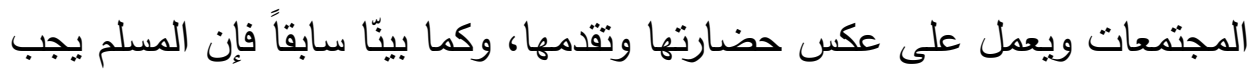
أن يتحلى بالأخلاق والآداب الإنسانية التي فطر الله الناس عليها، فالمسلم يتحلى لفئل

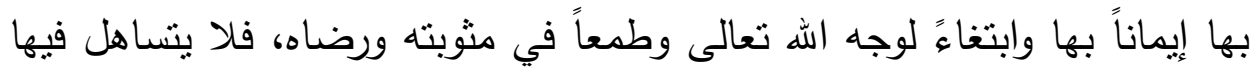

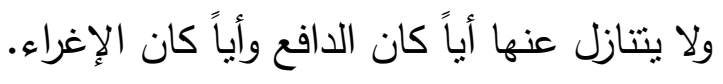


المصادر والمراجع والهوامش: أولاً: القرعان الكريم السنة النبوية النزان ثانياً:المراجع العربية:

1- انتصار ابراهيم محجوب، الإتكيت خلق وآداب اسلامية ط1 (الخرطوم: دار عزة للنشر والتوزيع، 2010م) 2-سعود بن عبد الله الحزيمي،الموسوعة الجامعة في الأخلاق والآداب، المجلد الأول، ط 1 (القاهرة: دار الفجر للنشر والتوزيع، 2005م)

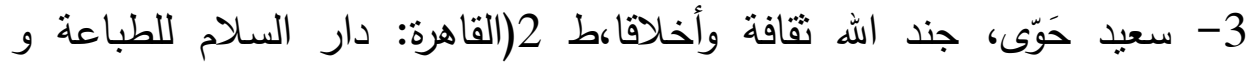

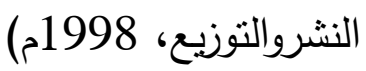
4-سيد قطب، في ظلد القرآن، ج 6. 5- عبد الفتاح سليم الزيني، المراسم والبرتكول، (الخرطوم: منشورات معهد الدراسات الدبلوماسية، 2006م). 6- محمد وقيع اله أحمد، أخلاقيات الحرب في الإسلام، (الاسكندرية: المكتب الجامعي الحديث، بدون تاريخ) 7- نبيل عشوش، فن الاتيكيت والبرتوكول، ط4 (القاهرة: بدون دار نشر، .)1999 
د. محمد يوسف إبراهيم - -المنظور الإسلامي للاتكيث، ص: 94-65

اللهوامش

1. سورة القلم، الآية رقم 4 ـ

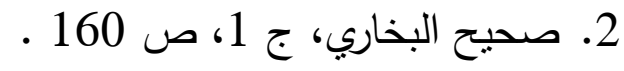

3. انتصار ابراهيم محجوب، الإتكيت خلق وآداب اسلامية ط1 (الخرطوم:دار

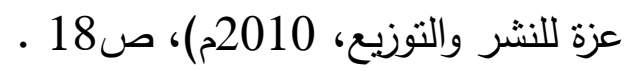

4. نبيل عشوش، فن الاتيكيت والبرتوكول، ط4 (القاهرة: بدون دار نشر،

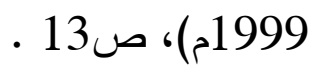

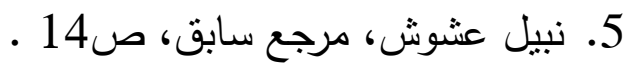

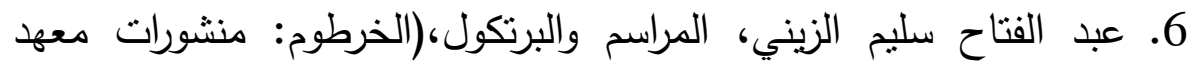

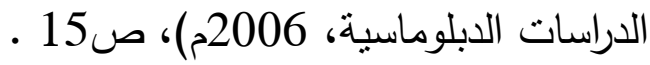

7. نبيل عشوش، مرجع سابق، ص13 .

8. محمد وقيع اله أحمد، أخلاقيات الحرب في الإسلام، (الاسكندرية: المكتب

الجامعي الحديث، بدون تاريخ)، ص 55.

9. سعود بن عبد الله الحزيمي،الموسوعة الجامعة في الأخلاق والآداب، المجلد

الأول، ط 1 (القاهرة: دار الفجر للنشر والتوزيع، 2005م)ص بله 15

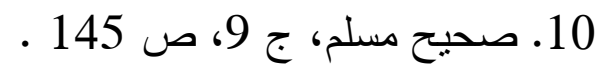

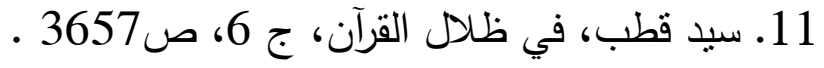

12. سنن الترمذي، ج 3، 438 . 43 .

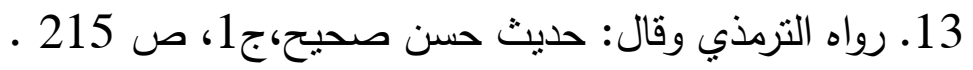

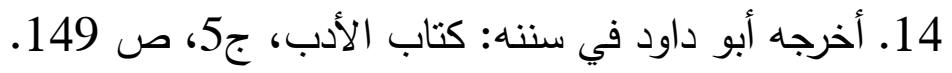

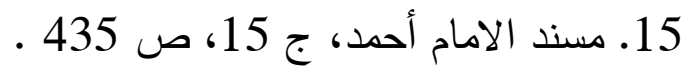

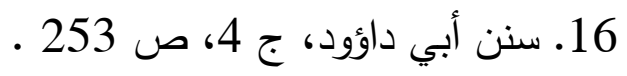


17. سعبد حَوّى، جند الله ثقافة وأخلاقا،ط 2(القاهرة: دار السلام للطباعة و

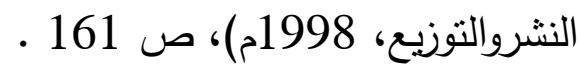

18.سورة النساء: الاية 86 .

19.سورة النور : الآية 27 . سورة النهاء

20. سورة النور : الآية 61 . الائ.

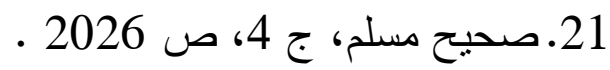

22. سنن الترمذي، ج 4، ص ص 23 184 .

23. سورة البلد: الآيات 8- 9 - 9 .

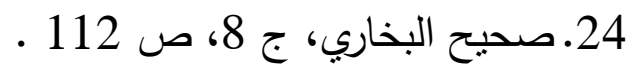

25.صحيح البخاري، ج 4، ص 56 . 56 .

26. رواه أحمد . 25

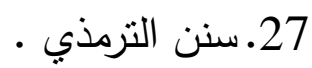

28. رواه أبو داؤود .

29. سورة لقمان: الآية 19 . 19

30. سورة الحجرات، الآية رقم 3.

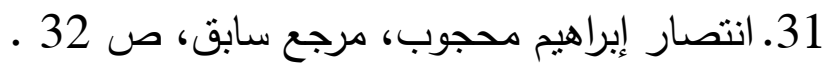

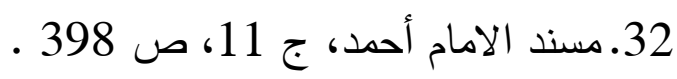

33. سورة الأعراف، الآية رقم 204 ـ 204

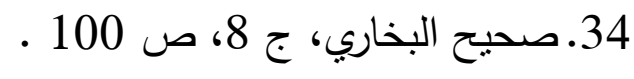

35.صحيح البخاري، ج 1، ص 35 . 35 .

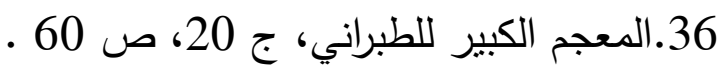

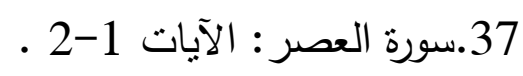

38.سورة الفجر ، الآيات 1-2 
د. محمد يوسف إبراهيم - -المنظور الإسلامي للاتكيث، ص: 94-65

39.سورة الليل، الآيات 1-2 .

40.صحيح البخاري، ج 8، ص 88 . 81 .

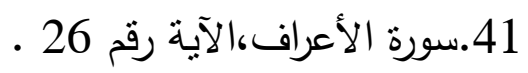

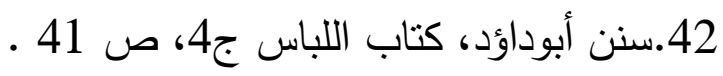

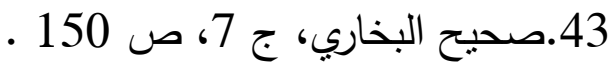

44.صحيح البخاري، ج 7، صـ 68 . 68 .

45.سورة التوبة، الآية رقم 108 . 108

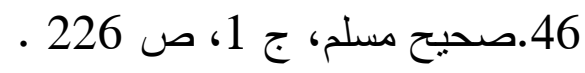

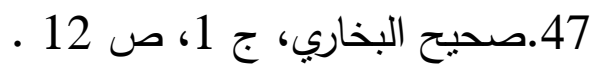

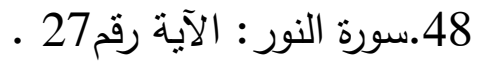

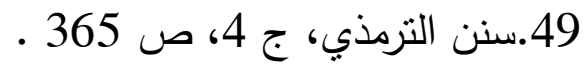

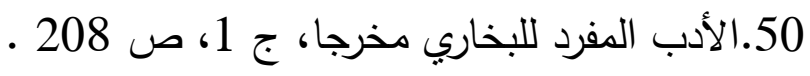

